\title{
Informing the measurement of wellbeing among young people living with HIV in sub-Saharan Africa for policy evaluations: a mixed-methods systematic review
}

Darshini Govindasamy ${ }^{1,2,3^{*}}$ (D), Janet Seeley ${ }^{1}$ (D), loana D. Olaru ${ }^{4,5}$ (D) Alison Wiyeh ${ }^{6,7}$, Catherine Mathews ${ }^{2,3}$ (D) and Giulia Ferrari ${ }^{1}$ (D)

\begin{abstract}
Young people living with HIV (YPLHIV) in sub-Saharan Africa (SSA) are at high risk of having a poor quality of life. Addressing wellbeing explicitly within HIV/AIDS policies could assist mitigation efforts. However, guidance on wellbeing measures to evaluate policies for YPLHIV is scarce. The aims of this mixed-methods review were to identify: i) key dimensions of wellbeing and ii) wellbeing measures that align to these dimensions among YPLHIV (15-24 years) in SSA. We searched six social science and medical databases, including grey literature. We included studies that examined correlates and lived experiences of wellbeing, among YPLHIV in SSA, from January 2000 to May 2019. Two reviewers independently screened abstracts and full texts and assessed methodological quality of included articles. We analysed quantitative and qualitative data using descriptive and meta-ethnographic approaches, respectively. Thereafter, we integrated findings using a framework approach. We identified 6527 citations. Of these, 10 quantitative and 30 qualitative studies were included. Being male, higher educational status, less stigma and more social support were likely correlates of wellbeing. Themes that shaped experiences suggestive of wellbeing were: 1) acceptance and belonging - stigma, social support; 2) coping; 3) standard of living. Our final synthesis found that the following dimensions potentially characterise wellbeing: self-acceptance, belonging, autonomy; positive relations, environmental mastery, purpose in life. Wellbeing for YPLHIV is multi-dimensional and relational. Relevant measures include the Personal Wellbeing Index, Ryff's Psychological Wellbeing Scale and Mental Health Continuum Short Form. However, psychometric evaluations of these scales among YPLHIV in SSA are needed.
\end{abstract}

Keywords: Wellbeing, Mental health, Dimensions, Measurement, Young people living with HIV, Mixed-methods review, Sub-Saharan Africa

\footnotetext{
* Correspondence: darshini.govindasamy@mrc.ac.za

1Department of Global Health and Development, Faculty of Public Health and Policy, London School of Hygiene and Tropical Medicine, London, UK ${ }^{2}$ Health Systems Research Unit, South African Medical Research Council, Francie van Zijl Drive, Parow Valley, PO Box 19070, Tygerberg 7501, South Africa

Full list of author information is available at the end of the article
}

(c) The Author(s). 2020 Open Access This article is licensed under a Creative Commons Attribution 4.0 International License, which permits use, sharing, adaptation, distribution and reproduction in any medium or format, as long as you give appropriate credit to the original author(s) and the source, provide a link to the Creative Commons licence, and indicate if changes were made. The images or other third party material in this article are included in the article's Creative Commons licence, unless indicated otherwise in a credit line to the material. If material is not included in the article's Creative Commons licence and your intended use is not permitted by statutory regulation or exceeds the permitted use, you will need to obtain permission directly from the copyright holder. To view a copy of this licence, visit http://creativecommons.org/licenses/by/4.0/ The Creative Commons Public Domain Dedication waiver (http://creativecommons.org/publicdomain/zero/1.0/) applies to the data made available in this article, unless otherwise stated in a credit line to the data. 


\section{Introduction}

Adolescence and young adulthood are critical periods for wellbeing, an indicator of the quality of life. This life stage is important for building human and social capital, resources that can sustain wellbeing in adulthood [1-3]. For young people living with HIV (YPLHIV), who because of greater access to anti-retroviral therapy (ART), can expect to reach adulthood, building and sustaining wellbeing as they grow older is crucial. In sub-Saharan Africa (SSA) there are an estimated 2.8 million YPLHIV aged 15-24 years [4]. Many YPLHIV in SSA are at high risk for HIV-related mortality, morbidity [5] and poor quality of life due to the sub-optimal access to treatment and psycho-social services, including exposure to multiple stigmas [6-9]. According to the United Nations [10], the number of YPLHIV in Africa is projected to increase by 44\% between 2015 and 2030. Models predict that investment in the quality of life among the growing youth population in SSA, particularly via addressing health needs, could increase labour productivity and resultantly accelerate economic growth [11]. If long-run economic growth is to be achieved, then public health policies need to also promote the wellbeing among YPLHIV, a vulnerable and growing population in this region.

In social psychology, wellbeing denotes a sense of thriving in multiple life domains such as family, career and health [12]. Two constructs of wellbeing exist, subjective wellbeing (SWB) which focuses on people's emotional and cognitive evaluations of their lives [13] and psychological wellbeing (PWB) which emphasise positive functioning, relationships and human potential $[14,15]$. The wellbeing of YPLHIV in SSA is likely to be compromised given the impact HIV/AIDS has on key dimensions of wellbeing such as finding meaning, selfacceptance and maintenance of positive caregiver and peer relationships [16]. Importantly, emerging empirical evidence has shown that YPLHIV in this setting are at high risk for depression and anxiety [17-19] and suicidal ideation [20]. Negative mental health functioning is one of the strongest predictors of wellbeing [21], and if experienced during adolescence may lead to reduced wellbeing in adulthood $[2,22]$, and subsequently unfavourable labour-market outcomes such as low earnings [23-25]. The risk of lowered wellbeing among YPLHIV is of major concern as econometric evidence has shown that the stocks and intergenerational transfer of human capital to young people in this region has already been eroded by the HIV/AIDS epidemic [26, 27].

In line with Sustainable Development Goal (SDG) 3 ("Ensure healthy lives and promote well-being for all at all ages"), wellbeing has emerged as a major policy outcome $[28,29]$. Substantial investment and progress has been made in reducing the HIV epidemic among young people (SDG 3.3) via scale-up of HIV testing and access to treatment [30, 31]. Yet, promoting mental health and wellbeing (SDG 3.4) among young people has received very little attention. There is growing recognition for the need to include quality of life as an HIV/AIDS programme target $[32,33]$. Current multi-sectoral HIV programmes are focused on reducing new HIVinfections among adolescent girls and young women via improving access to health and social services, including economic opportunities [34]. However, monitoring and evaluation frameworks of these programmes do not explicitly include wellbeing as an outcome, a recommended measure in the field of economics for measuring social progress [35]. Valuing only narrow health outcomes in health economic analyses may fail to capture the broader impacts of the multi-sectoral initiatives that go beyond health [36, 37]. From a public health financing perspective, understanding the impact of HIV policies on wellbeing could provide a range of ways to direct and strengthen investments for YPLHIV.

Wellbeing measures are used in economic policy evaluations as empirical approximations of individual welfare (i.e. the satisfaction (utility) gained from consuming a good or service) [38]. Of the few health-related economic studies that have examined wellbeing among children and adolescents, most have used uni-dimensional life satisfaction measures [39, 40]. However, several multi-dimensional wellbeing measures developed for young people in the Global North exist in the field of social psychology, these include multi-dimensional SWB scales (i.e. Student Life Satisfaction Scale [41], Personal Wellbeing Index [42]), and PWB measures (Ryff Scale of PWB [43], Mental Health Continuum Short-Form [44]). In the field of HIV/AIDS epidemiology, health-related quality of life measures that encompass some wellbeing dimensions such as emotional and social functioning have been recommended [45] and applied among adolescents living with HIV, these include the Paediatric Quality of Life Inventory [46], KIDSCREEN [47], WHO Quality of Life [48]. However, there is a lack of guidance on which wellbeing measures, underpinned by wellbeing theory, are appropriate for health economic surveys seeking to evaluate the impact of HIV policies on the wellbeing of YPLHIV.

Wellbeing may be conceptualised, experienced, and valued differently across cultures. A better understanding of the correlates and local experiences of wellbeing among YPLHIV in SSA and how these relate to international conceptualisations of wellbeing is required in the selection of culturally sensitive, yet generalisable, measures of wellbeing for SSA. While several studies have explored wellbeing among young people in this sub-region $[49,50]$, to the best of our knowledge, no study has systematically reviewed the evidence on what constitutes wellbeing among YPLHIV on the continent. 
The objectives of this mixed-methods review are to identify and critically assess: 1) quantitative evidence on the correlates of wellbeing among YPLHIV; 2) qualitative evidence on the lived experiences of wellbeing among YPLHIV; 3) integrate these two strands of evidence and identify appropriate measures of wellbeing based on key dimensions of wellbeing relevant to YPLHIV.

The main reason for using quantitative and qualitative evidence in this review is to provide a broad perspective in order to gain a detailed and thorough understanding of the indicators of wellbeing and potential mechanisms by which factors influence wellbeing [51-53]. The findings from this review could guide the selection of wellbeing measures for policy evaluations focused on YPLHIV.

\section{Methods}

The quantitative review was prepared in accordance with Preferred Reporting Items for Systematic Reviews and Meta-analysis (PRISMA) checklist [54] (Additional file 1). Whereas the qualitative review adhered to the Enhancing transparency in reporting the synthesis of qualitative research (ENTREQ) statement [55] (Additional file 2 ). Reporting of this review was informed by mixedmethod review guidelines [56].

\section{Epistemological perspective and study design}

We adopted a relational wellbeing perspective as increasing research from the fields of social psychology, anthropology and international development have highlighted that relationships are central to the experiences of wellbeing in low- and middle-income countries, particularly studies from SSA [57-59]. We drew on the relationality meaning model as proposed by Wissing [60] as relationships and connections have been shown to be central to formation of wellbeing among young people [61-65]. According to the relationality meaning model, relationships, with self (intrapersonal) and others (interpersonal) are at the centre of a meaningful life, and play an important role in the connections between people and context (i.e. social, cultural, ecological, physical, spiritual) [60]. This model has a strong PWB orientation and emphasises three key elements: 1. meaning of life (experienced in the connectedness to something larger than life and the realisation of values); 2. meaning in life (experienced in the belongingness and relatedness to other people); and 3. meaning to life (expressed via actions such as expressions of affection, longing for belongingness, building relationships). This model hypothesises that meaning of life facilitates the construction of meaning in life which in turn directs activities to provide meaning to life [60]. We specifically applied elements of this model to understand the pathways to wellbeing in order to elucidate dimensions that are relevant in capturing the wellbeing among YPLHIV.

The mixed-methods approach used was a segregated (convergent) design [66]. We selected this design because we regarded quantitative and qualitative research as complementary. However, we conducted the quantitative and qualitative review separately as different approaches were used and the review criteria differed. For the quantitative review, we followed systematic review methods used in evidenced-based medicine [67]. Whereas for the qualitative review, we used a flexible meta-ethnography design [68]. Quantitative and qualitative studies were retrieved, analysed and synthesised separately, prior to the final synthesis [66].

\section{Eligibility}

The criteria for inclusion of studies are summarised in Table 1.

\section{Studies}

We included published and non-published quantitative and qualitative studies. We selected observational quantitative studies reporting on primary or secondary data analysis from cohort or cross-sectional datasets. We deemed any qualitative study design, data collection technique (e.g. group interviews, in-depth interviews, participant observations) or analytical approach (e.g. thematic analysis, framework analysis) eligible for the qualitative arm of this review. Furthermore, we included mixed-method studies that satisfied corresponding inclusion and exclusion criteria, separately determining eligibility for quantitative and qualitative components. In addition, we scanned the bibliographies of relevant quantitative or qualitative reviews to identify potentially eligible primary studies not yielded by the primary search.

\section{Participants}

We selected studies focused on young people, defined as older adolescents and young adults between the ages of 15-24 years, who were living with HIV [69]. We focused on this condition only as HIV/AIDS remains the leading cause of mortality among young people in this region $[70,71]$. We included studies if at least the average age of the sample was within our age-range or results could be extractable for the age-range.

\section{Outcome measures}

Drawing from the field of social psychology, we conceptualised wellbeing as subjective and psychological. Thus, our outcome measures included any dimension of these two constructs: 1) subjective- positive and negative affect (mood states, emotions), life satisfaction [13]; 2) psychological- self-acceptance, positive 
Table 1 Eligibility criteria for quantitative and qualitative studies

\begin{tabular}{|c|c|c|}
\hline & Inclusion & Exclusion \\
\hline \multicolumn{3}{|c|}{ Quantitative studies } \\
\hline Population & • Young people living with HIV (aged 15-24 years) & $\begin{array}{l}\text { - Studies were }<50 \% \text { of the population is between the ages of } \\
15-24 \text { years } \\
\text { - Studies that focus on specific population groups (i.e. orphans, } \\
\text { LGBTQl, pregnant or post-partum women, sex workers, home- } \\
\text { less youth, patients with co-morbidity) }\end{array}$ \\
\hline Study design & $\begin{array}{l}\text { - Observational research study designs or standard of care arm } \\
\text { from a trial } \\
\text { - Studies that statistically examined factors associated with } \\
\text { subjective or psychological wellbeing or any of its dimensions } \\
\text { using regression techniques } \\
\text { - Studies that statistically examined factors associated with } \\
\text { mental health (i.e. mental illness- depression, anxiety) using } \\
\text { regression techniques }\end{array}$ & $\begin{array}{l}\text { - Letters, opinion pieces, editorials, reviews, qualitative studies } \\
\text { - Psychometric evaluations } \\
\text { - Studies were the sample size is } n<50\end{array}$ \\
\hline Outcomes & $\begin{array}{l}\text { - Predictors of any dimension of subjective or psychological } \\
\text { wellbeing or mental health }\end{array}$ & $\begin{array}{l}\text { - Outcomes related to physical functioning } \\
\text { - Outcomes related to objective measures of quality of life (i.e. } \\
\text { birth rate, school completion, mortality) }\end{array}$ \\
\hline Other & $\begin{array}{l}\text { - Peer-reviewed journal articles and non-published studies (con- } \\
\text { ference abstracts, dissertations, working papers) } \\
\text { - English and non-English studies } \\
\text { - Studies conducted between January 2000-May } 2019\end{array}$ & \\
\hline \multicolumn{3}{|c|}{ Qualitative studies } \\
\hline Sample & $\begin{array}{l}\text { - Young people living with HIV (aged 15-24 years) } \\
\text { - Caregivers of young people aged 15-24 years, healthcare } \\
\text { workers, educators, other family members }\end{array}$ & $\begin{array}{l}\text { - Studies that focus on specific population groups (i.e. orphans, } \\
\text { LGBTQI, pregnant or post-partum women, sex workers, home- } \\
\text { less youth, patients with co-morbidity) }\end{array}$ \\
\hline $\begin{array}{l}\text { Phenomenon } \\
\text { of interest }\end{array}$ & - Subjective and psychological wellbeing, mental health & - Studies examining objective measures of quality of life \\
\hline Design & $\begin{array}{l}\text { - Studies incorporating any form of qualitative study design, data } \\
\text { collection method or analytical technique } \\
\text { - Cross-sectional or longitudinal }\end{array}$ & $\begin{array}{l}\text { - Studies with YPLHIV in the intervention arm of a trial } \\
\text { - Reviews, editorials, letters, essays, theoretical and opinion } \\
\text { papers } \\
\text { - Studies evaluating a specific policy, programme or intervention }\end{array}$ \\
\hline Evaluation & $\begin{array}{l}\text { - Studies aimed at understanding the lived experiences of } \\
\text { wellbeing or experiences related to any dimension of wellbeing } \\
\text { or mental health }\end{array}$ & $\begin{array}{l}\text { - Narrow focus on physical functioning, ART adherence, } \\
\text { disclosure challenges, sexual reproductive health needs }\end{array}$ \\
\hline $\begin{array}{l}\text { Research } \\
\text { type }\end{array}$ & - Qualitative or mixed-methods & - Quantitative studies \\
\hline Other & $\begin{array}{l}\text { - Peer-reviewed journal articles and non-published studies (con- } \\
\text { ference abstracts, dissertations, working papers) } \\
\text { - English and non-English studies } \\
\text { - Studies conducted between January 2000-May } 2019\end{array}$ & \\
\hline
\end{tabular}

relations, environmental mastery, autonomy, purpose in life, personal growth $[43,72]$. Given the strong correlation between mental health and wellbeing [21, $72,73]$, we included mental health as one of our outcome measures. We applied a biomedical definition of mental health (i.e. the absence or presence of symptoms of mental illness) [74, 75].

We included: quantitative studies that assessed factors associated with any dimension of wellbeing or mental health using statistical regression techniques; qualitative studies that explored lived experiences of wellbeing or experiences related to dimensions of wellbeing or mental health.

\section{Study setting}

We included studies conducted in any setting (e.g. household, clinic, school) in a country within the sub-
Saharan African region, as per the World Bank country classification [76]. We chose to focus on SSA only as this region accounts for the highest number of YPLHIV [77]. Furthermore, young people living in this region have the highest risk of HIV acquisition [78].

\section{Time and language}

We restricted the search to studies conducted between 01 January 2000 and 11 May 2019. This timeline covers the key post-ART periods in SSA: 1) ART introduction (2000-2007); 2) expanded ART (2008-2010); and 3) scaled-up ART (2011-2019) [79]. We considered the post-ART period more relevant to the current international HIV policy landscape as treatment for all HIVpositive individuals is now the recommended approach [80]. No language restrictions were placed on the search. 


\section{Information sources}

Aiming for a broad interdisciplinary approach, we searched published and grey literature on multiple electronic platforms. We searched 6 electronic databases for eligible peer-reviewed journal articles: Medline, Web of Science, PsychINFO, Econlit, Africa-Wide Information, International Bibliography of the Social Sciences. For grey literature, we searched the dissertation databases (Dissertations and Theses- A\&I, World Cat), and the International AIDS Society conference archives (20012018). In addition, eligible working papers were identified by searching data repositories of the Organisation for Economic Co-operation and Development, IDEAS and the National Bureau of Economic Research.

\section{Search strategy}

We searched electronic databases using either compound search strategies containing subject headings that were supplemented with text terms (Additional files 3, 4, 5 and 6) and JEL codes (Additional file 5), or simple Boolean logic search strategies with keywords (Additional files 7, 8, 9 and 10). Our search terms were aligned to dimensions of the subjective and psychological wellbeing constructs (e.g. negative and positive affect, life satisfaction, self-acceptance, social relationships) $[13,72]$, with a specific focus on relational dimensions. In addition, our search included terms related to the attitudes and symptoms of common mental disorders (i.e. depression, anxiety) among YPLHIV [81].

\section{Study records- data management, selection process, data collection process}

We imported search outputs into an EndNote (X 8) library and removed duplicate references. Thereafter, we imported this library into an online systematic review manager (Covidence systematic review software, Veritas Health Innovation, Australia). DG and IDA dual screened titles and abstracts independently, and $10 \%$ of these were dual screened by GF. AW assisted DG with the dual screening of grey literature. DG subsequently resolved conflicts via discussion with the dual screener, obtained the full text for all potentially eligible abstracts and applied the inclusion criteria to these studies. GF, JS, CM randomly checked all full texts. Less than 5\% of abstracts were non-English language studies. For these specific studies, we obtained a translated electronic English version of the study.

\section{Data items}

Once consensus was reached on eligible studies, DG entered relevant data from potentially eligible studies onto electronic data extraction forms. The design of these forms were informed by the Strengthening the Reporting of Observational Studies in Epidemiology (STROBE) checklist [82] and Consolidated criteria for Reporting Qualitative Research (COREQ) checklist [83], for quantitative and qualitative studies, respectively.

We extracted information on the following variables from each included study: author, year published, study setting, country income classification [76], design, outcome definition, analytical techniques, participant demographics, treatment status, disclosure status. For quantitative studies, we specifically extracted data from regression models (e.g. sample size, measures of associations, confidence intervals and $p$-values). For qualitative studies, we extracted primary themes or first order constructs (i.e. participants' understanding as reported in the study via verbatim quotes or authors description), and secondary themes or second order constructs (i.e. authors' interpretations of participants' understandings). Co-authors randomly checked data extractions.

\section{Outcomes}

a) Quantitative: explanatory variables associated with wellbeing or mental health, and wellbeing and mental health measures.

b) Qualitative: meanings and manifestations of wellbeing, any dimension of wellbeing or mental health

\section{Quality appraisal}

All potentially eligible studies were critically appraised by assessing their methodological quality. For quantitative studies, we applied a risk of bias tool, adapted from the Cochrane guidance on assessing risk of bias in non-randomised studies [67]. DG and GF selected items for this tool based on their relevance to observational study designs in epidemiology and psychology. Studies were categorised into three groups, depending on the level of bias: low, medium or high risk of bias. This was assessed by evaluating measures applied to reduce the following biases: 1) selection bias - random sampling techniques; 2) information bias - training of interviewers in the administration of the scale, translation of the scale to local language, assessing the validity and reliability of scale for given population; 3) confounding - adjustments for potential confounders. For qualitative studies, we applied a quality assessment tool adapted from the COREQ checklist [83] and key studies [84, 85]. DG and JS selected the following indicators for this tool based on its relevance to qualitative research design 1) rigor use of appropriate theoretical frameworks, sufficient data collected; 2) sincerity - self-reflexivity, transparency about the methods and challenges; 3 ) credibility - triangulation of data, inductive nature of derived themes. 


\section{Data analysis-synthesis}

We conducted a simple descriptive analysis of key quantitative findings. We categorised studies by country income classification and SSA sub-region as the quality of life among YPLHIV may vary depending on the country's healthcare resources and HIV-epidemic pattern specific to that sub-region. For the qualitative studies, we applied meta-ethnographic analytical methods [86], as implemented by Atkins, Lewin [87]. We specifically used the reciprocal translation analytical approach to develop themes. This approach entailed analysing and synthesising participant views (first-order construct) and authors' interpretation (second order constructs) to develop third-order constructs. We implemented this approach by comparing first and second order constructs across studies that were homogeneous in terms of design elements (setting, population and period of ART rollout) and chronologically ordered studies based on publication date [87]. Subsequently, we matched themes across papers ensuring the third order captured similar themes from various studies. We then tabulated translations by highlighting key third order constructs derived and supporting quotes and narratives. Finally, we interpreted the themes across studies to develop a line-of- argument synthesis describing how all themes interacted to shape wellbeing. We evaluated the quality of the qualitative evidence synthesis using the GRADECERQual (Confidence in Evidence from Reviews of Qualitative research) approach [88]. This approach includes an assessment of the methodological limitations, coherence, relevance, and adequacy. Lastly, we integrated the main quantitative and qualitative findings by mapping key correlates and themes that emerged from the data to subjective and psychological wellbeing dimensions [13, 72]. Thereafter, we interpreted our data drawing on the relationality meaning model [60].

\section{Results}

\section{Screening protocol}

The electronic database search yielded a total of 7563 citations, and our grey literature and manual search yielded 771 citations (Fig. 1). After removal of duplicate entries, 6527 studies were evaluated using title and abstracts; 5909 citations were excluded as these were based on populations that were not in line with the reviews' study population (i.e. caregivers, older adults, elderly, pregnant women) or outcome (i.e. drug effectiveness, access to education or sexual reproductive health services).

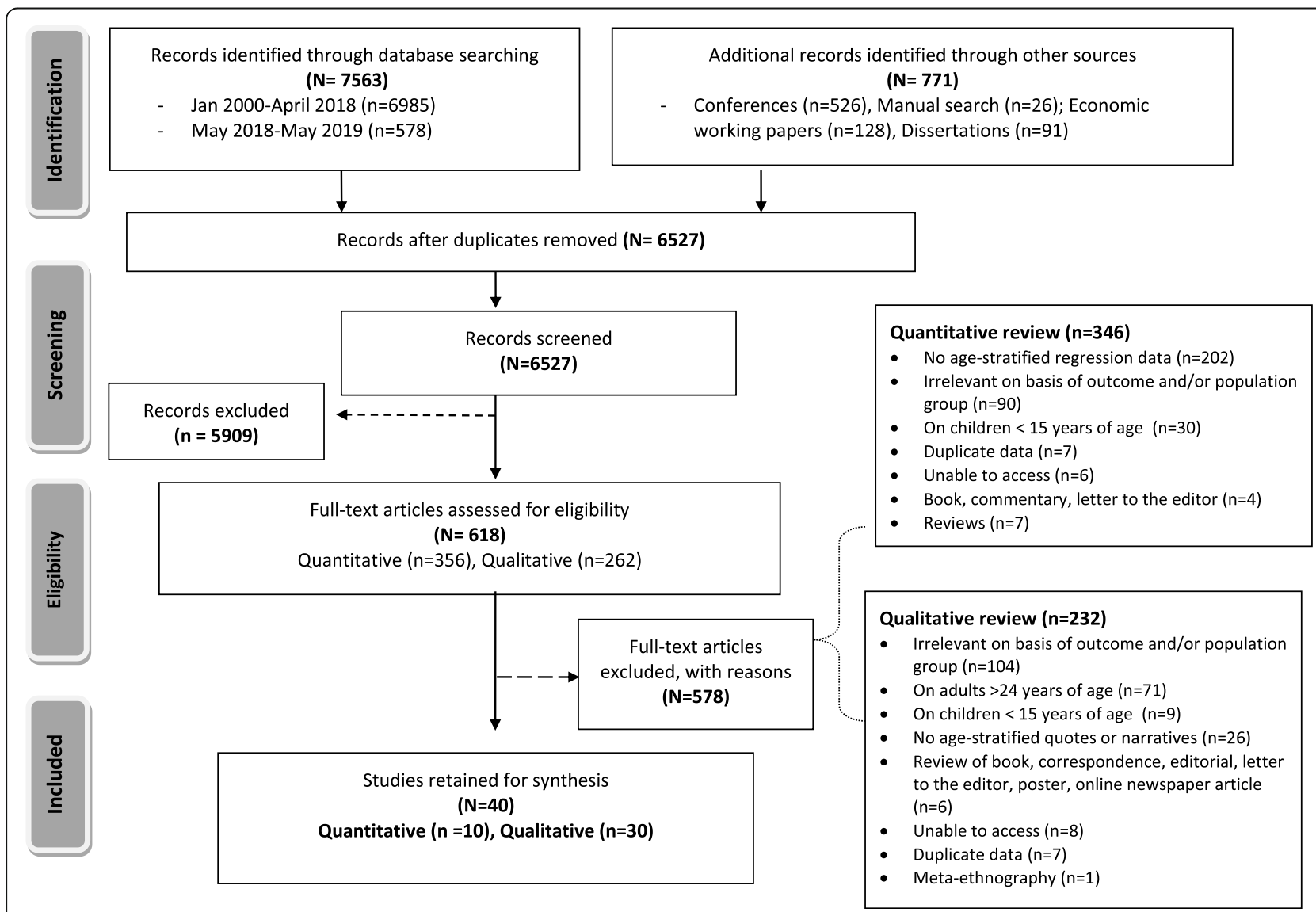

Fig. 1 Selection process for the inclusion of studies 
The remaining 618 potentially eligible studies were retrieved for full-text assessment (356 quantitative review, 262 qualitative review). Of the 356 citations identified for the quantitative review, 10 studies were included, and 346 studies excluded mainly due to the lack of agestratified analyses or focus on a biomedical outcome measure. Of the 262 citations identified for the qualitative review, 30 studies were included, and 232 studies were excluded mainly because of: 1 . a narrow focus on barriers to disclosure or adherence; 2. examined outcomes not related to subjective or psychological wellbeing dimensions (e.g. feasibility and acceptability of a biomedical intervention or health service programme); 3 . included adolescents or young adults in the sample but did not provide quotes from participants that spanned the age-range $15-24$ years.

\section{Overall study characteristics}

Tables 2 and 3 summarize the main characteristics of the 40 studies (10 quantitative and 30 qualitative). These studies were equally representative of the eastern and southern sub-regions of SSA, with nearly $50 \%$ conducted in low-income country settings $(n=19)$. The majority were conducted during the scaled-up ART phase. Participants were mainly between 15 to 19 years of age and sampled from urban public healthcare facilities. None of the included studies defined wellbeing in terms of subjective or psychological wellbeing as defined by Diener and Ryan [89] and Ryff and Keyes [72], respectively. However, these studies examined dimensions related to these constructs such as mental health, relationships and self-acceptance.

\section{Quantitative studies-characteristics and data synthesis}

Of the ten quantitative studies (Table 2), five were conducted in southern Africa: South Africa [90, 91], Namibia [92], Malawi [93], Zambia [94] (Table 3). The remainder conducted in eastern Africa: Uganda $(n=2)$ [95, 96], Kenya $(n=1)$ [97], Ethiopia $(n=1)$ [98] and Tanzania $(n=1)$ [99]. All studies employed a crosssectional study design. Neither subjective nor psychological wellbeing were measured in any of these studies. All studies measured mental health, specifically symptoms of depression, mainly using the Beck Depression Inventory-II $(n=3)$, Patient Health Questionnaire-9 $(n=$ $2)$, Strengths and Difficulties Questionnaire $(n=2)$. The key factors associated with mental health outcomes measured are detailed below (Table 4, Additional file 11).

\section{i. Demographics}

Being female was strongly correlated with poor mental health functioning in four studies (note, the outcome definition was different in each of the four studies) [92,
93, 96, 99]. The largest gender effect was observed in Malawi, with females almost eight times as likely compared to males to exhibit higher depression-related symptoms scores $(\beta=2.13,95 \%$ CI [0.82-3.43], $p=$ 0.002) [93]. In two urban studies from low income settings, there was between an 8 to $23 \%$ increase in depression scores with age [93, 99].

\section{ii. Standard of living}

Educational attainment was found to have a protective effect on mental health functioning in three low income countries [93, 95, 99]. In the Ugandan study, those with secondary school attainment were five times more likely to have better mental health than those with no education (adjusted odd ratio $(\mathrm{aOR})=5.3$, 95\% CI $[1.86-$ 15.41], $p<0.00)$ [95].

\section{iii. Psycho-social}

HIV-related stigma was strongly positively associated with poor mental health functioning in six studies [91, 92, 94, 96, 98, 99]. Among these studies, the largest effect of stigma was documented in Zambia, which found that the odds of having higher depressive symptom scores was almost three times higher for YPLHIV who experienced stigma than in those who did not $(\mathrm{aOR}=$ 2.99; 95\% CI [1.07-8.41], $p=0.01$ ) [94]. Having someone to talk to or feeling satisfied with health services or the social support received promoted positive mental health functioning in four studies (Namibia $(n=1)$ [92], Uganda $(n=2)$ [95, 96], Zambia $(n=1)$ [94]. In an Ethiopian study, Abebe, Shumet [98] reported that those with low social support were 2.74 times more likely to develop depressive symptoms than those with strong social support (95\% CI [1.42-5.27], $p=<0.01$ ). Moreover, poor adherence was positively correlated with depressive symptoms in three studies [97-99].

\section{Quality of studies}

Five of the ten quantitative studies were judged as having low quality as findings were subject to a high risk of bias [90-92, 94, 99] (Table 5). The main quality concerns in these studies were the lack of reporting on psychometric properties of the scale and standardisation of scale administration, including the inadequate reporting and interpretation of statistical analyses. Only one study psychometrically evaluated the chosen scale on a similar study population and found it to have good validity and reliability [93]. None of the studies reported information on the cultural validity of the chosen scale/s. All studies were subject to selection bias as samples were drawn from healthcare facilities, primarily using non-random sampling techniques. 


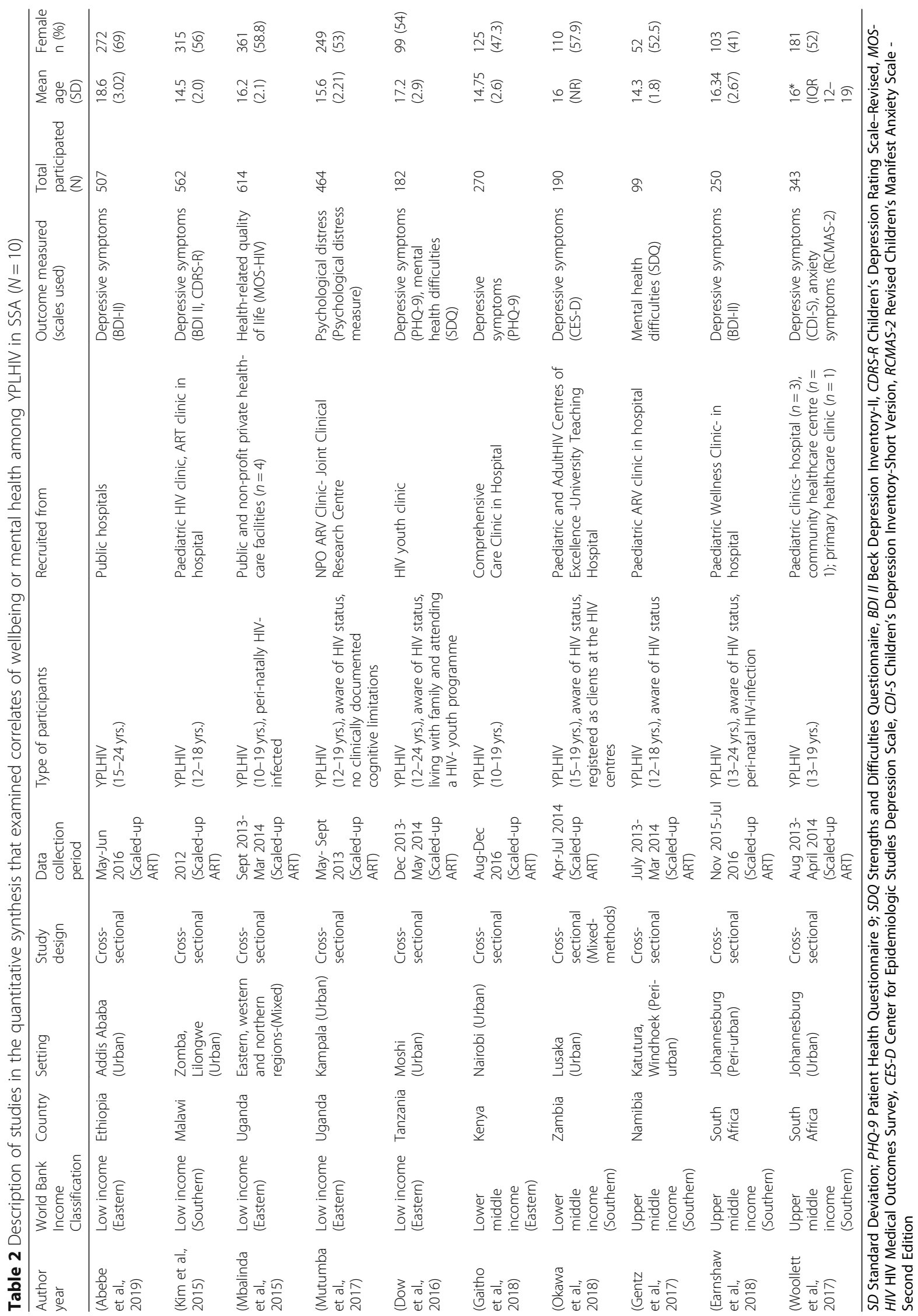




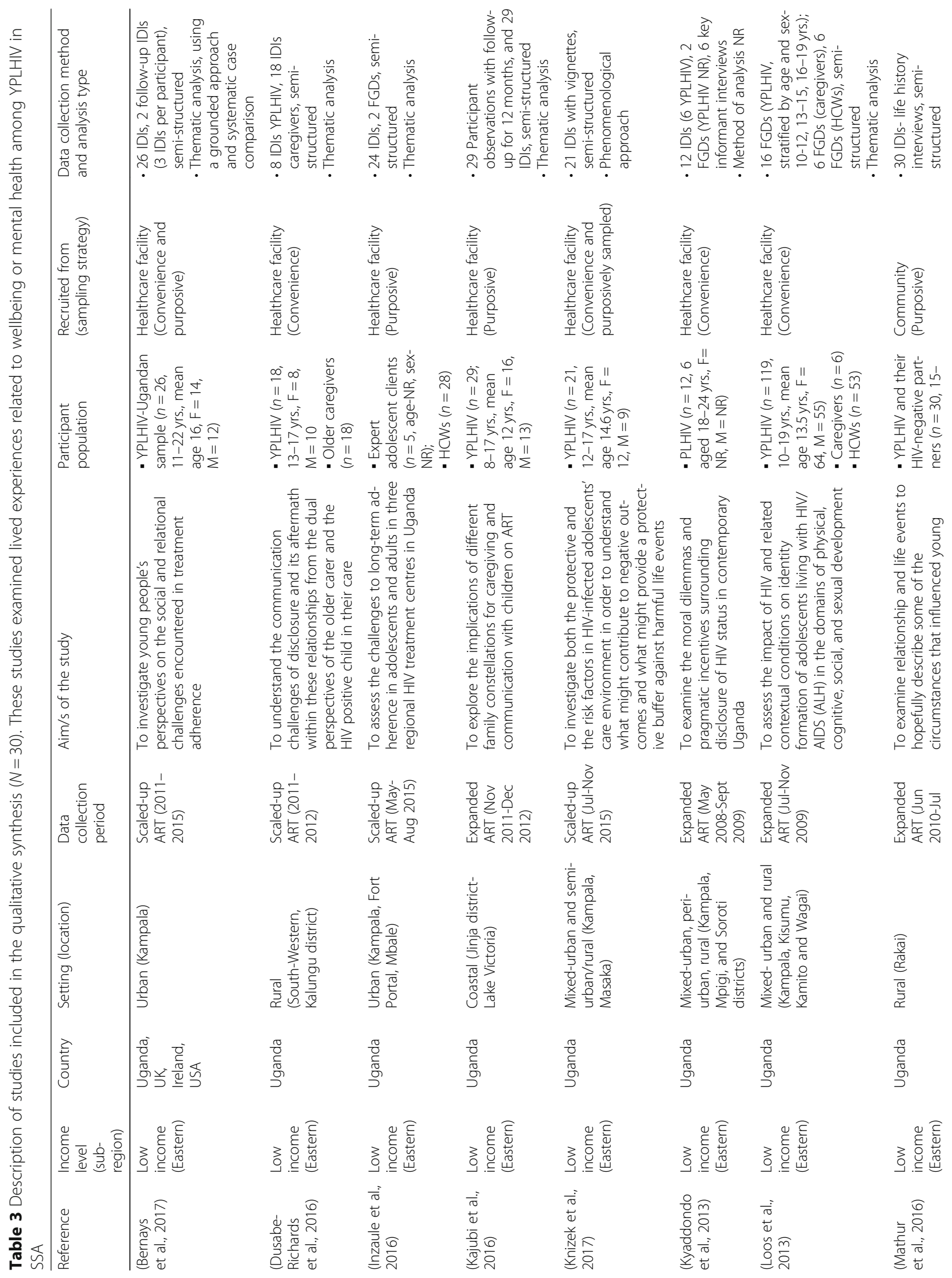




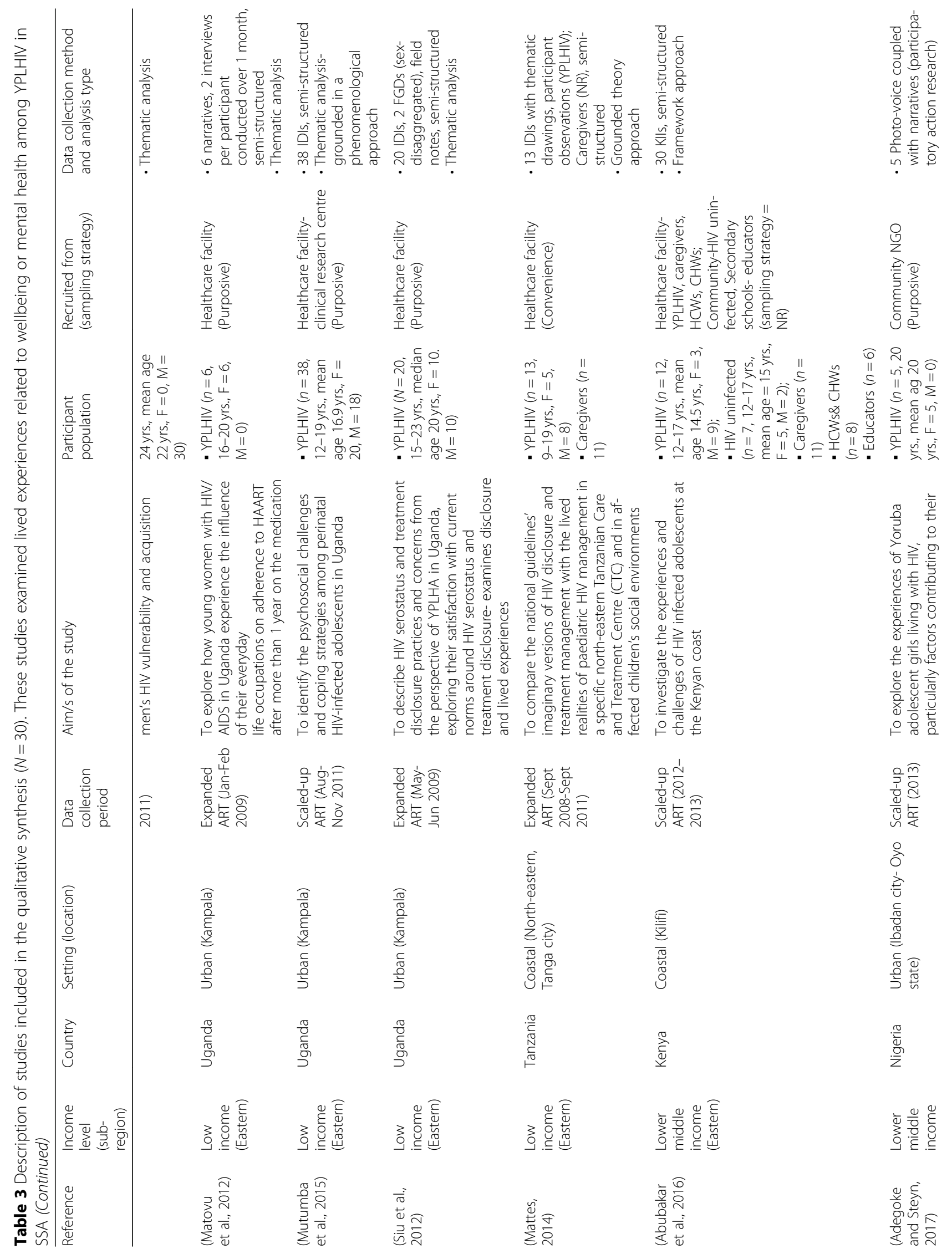




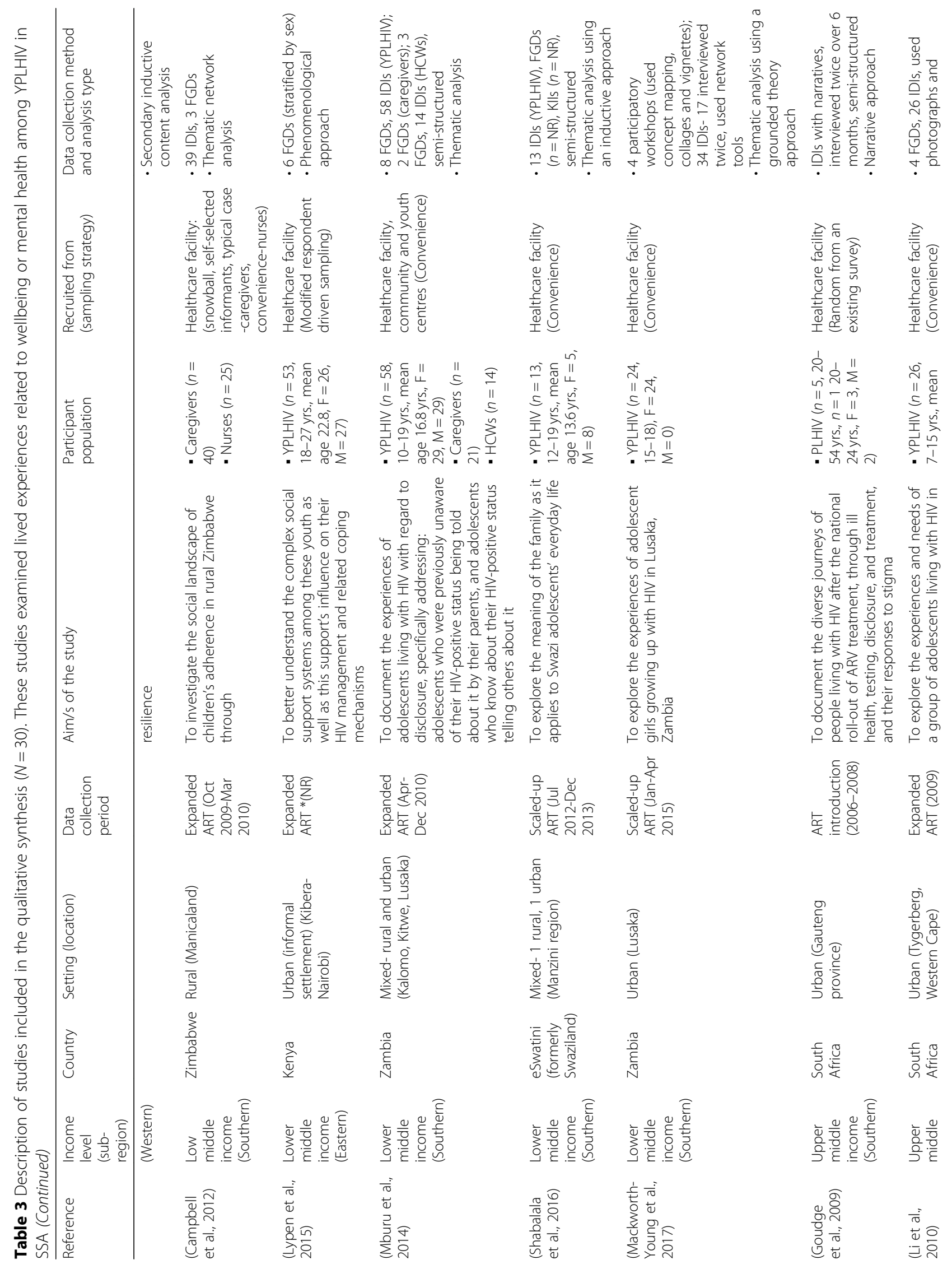




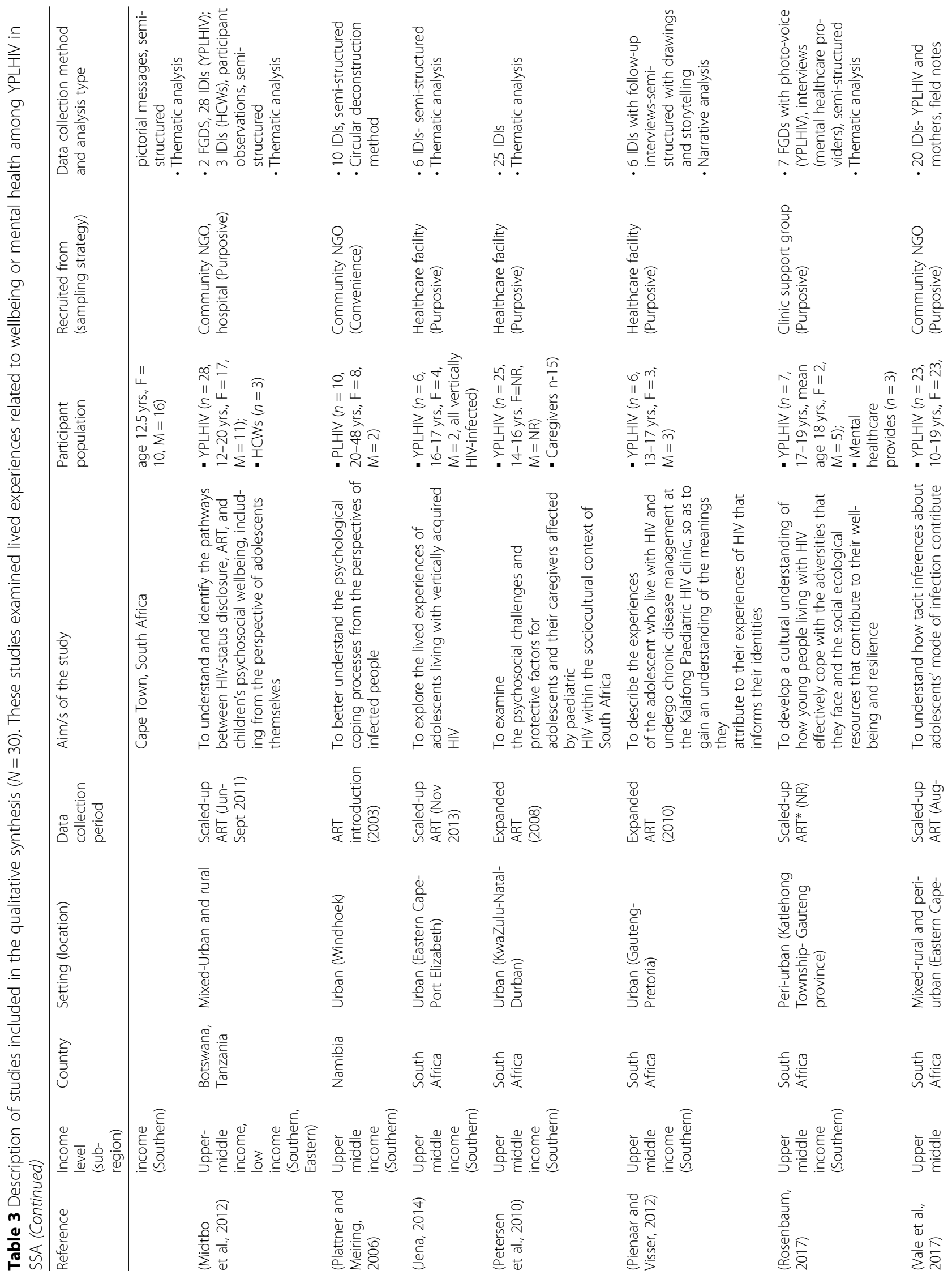




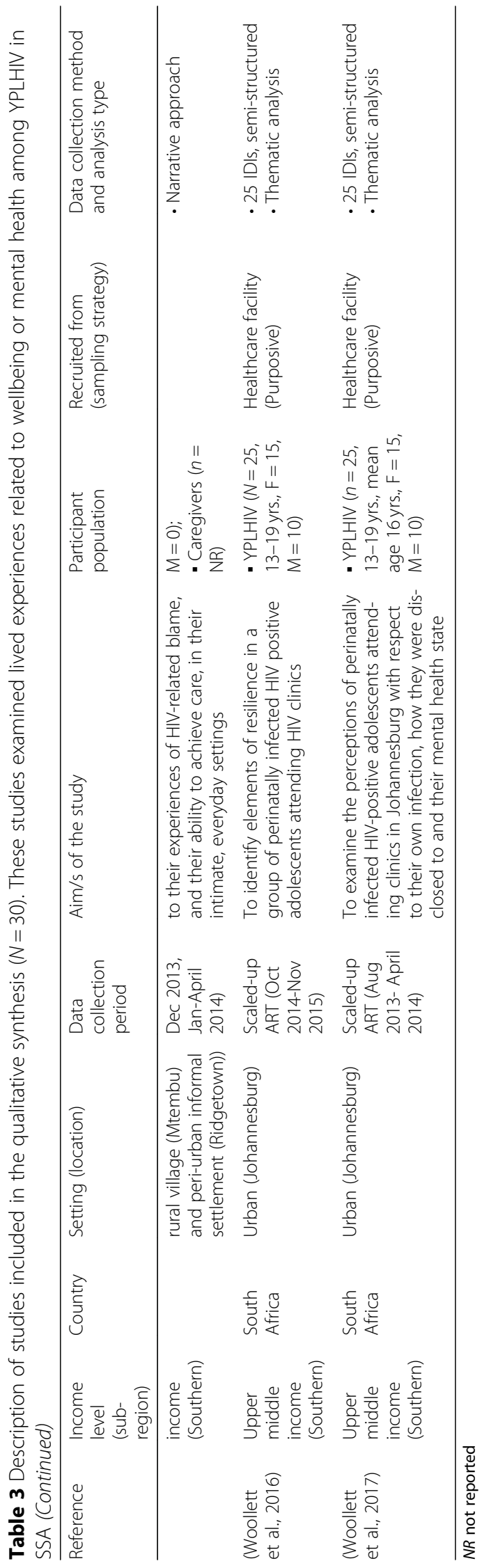




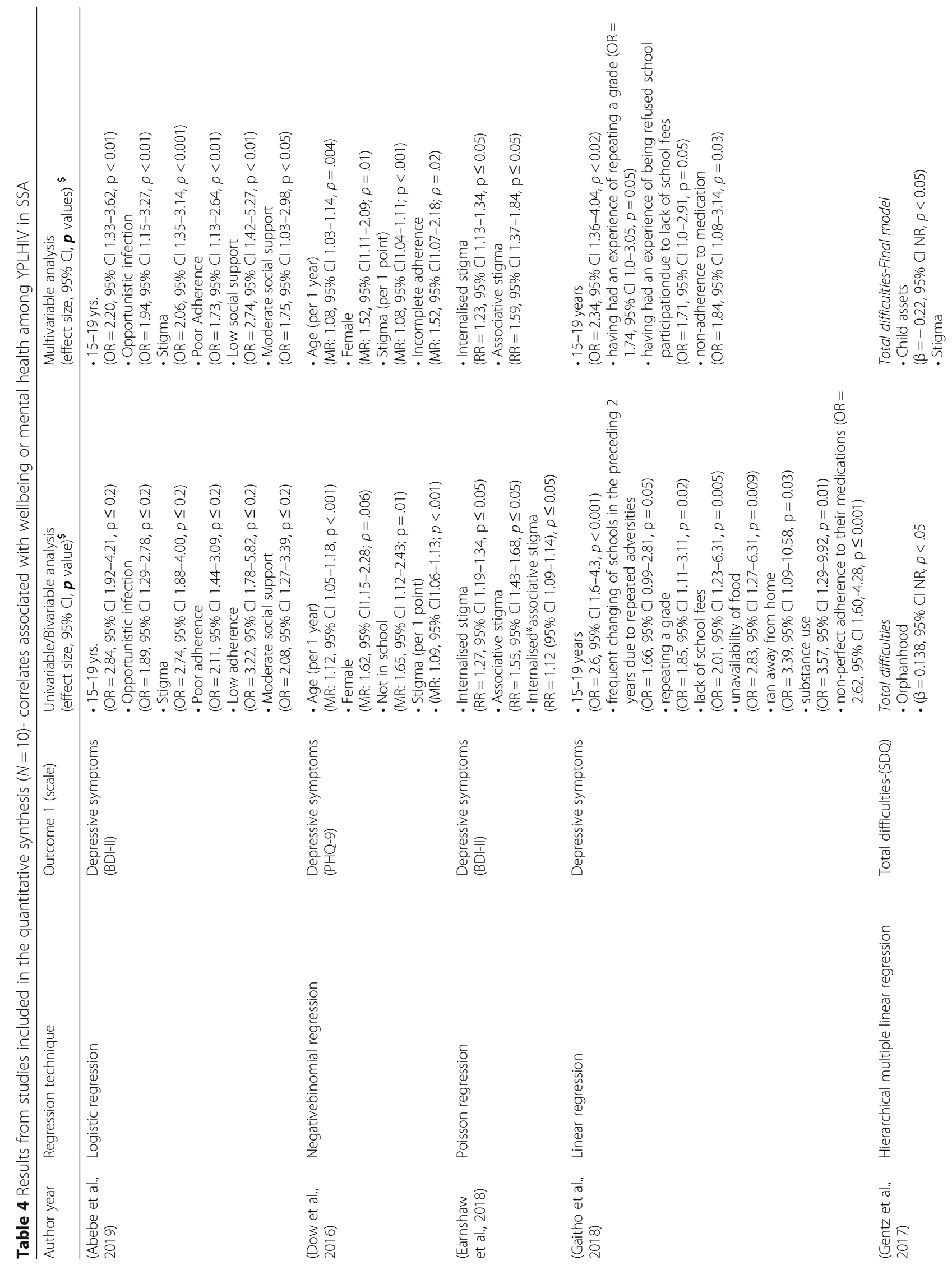


Govindasamy et al. Health and Quality of Life Outcomes

(2020) $18: 120$

Page 15 of 34

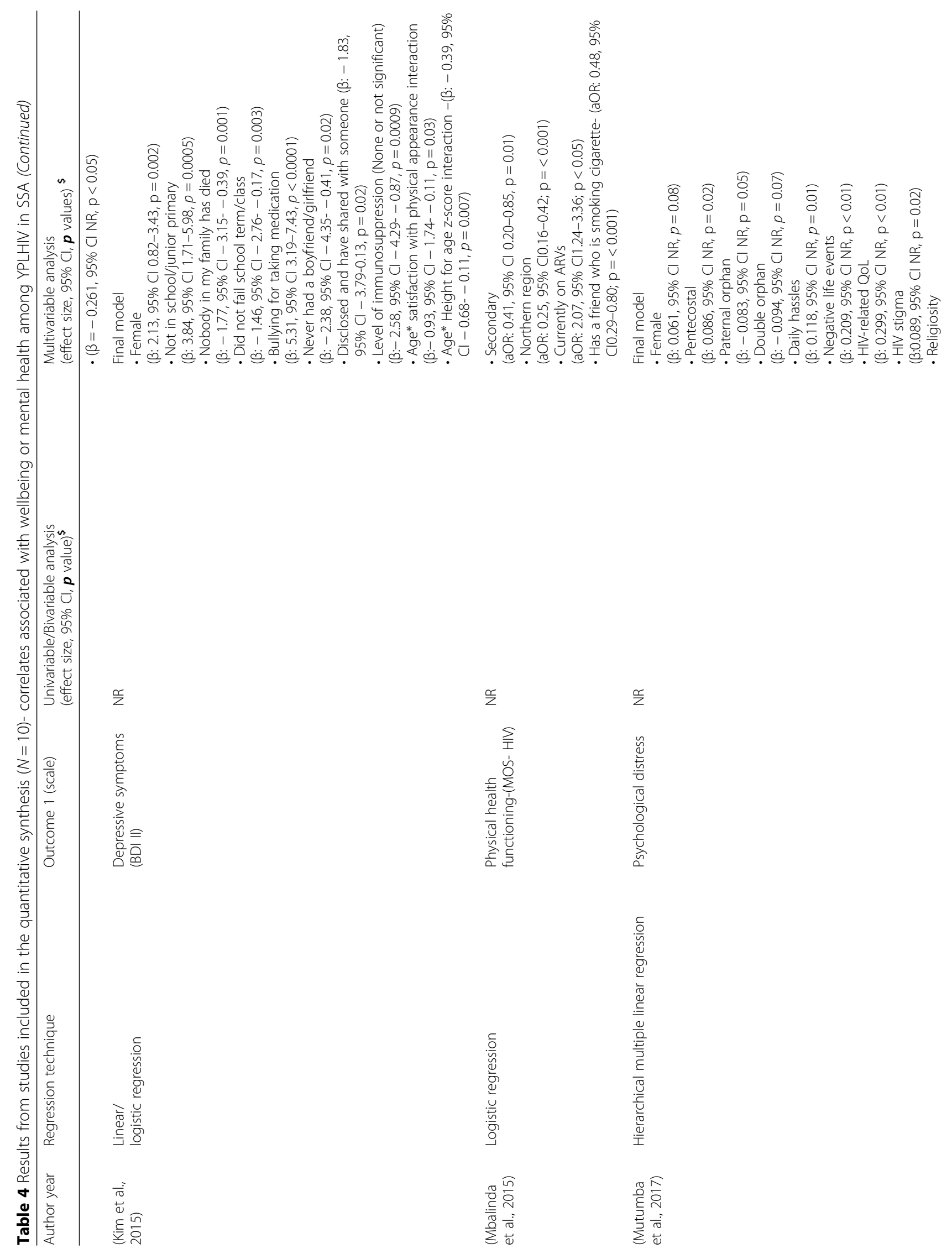




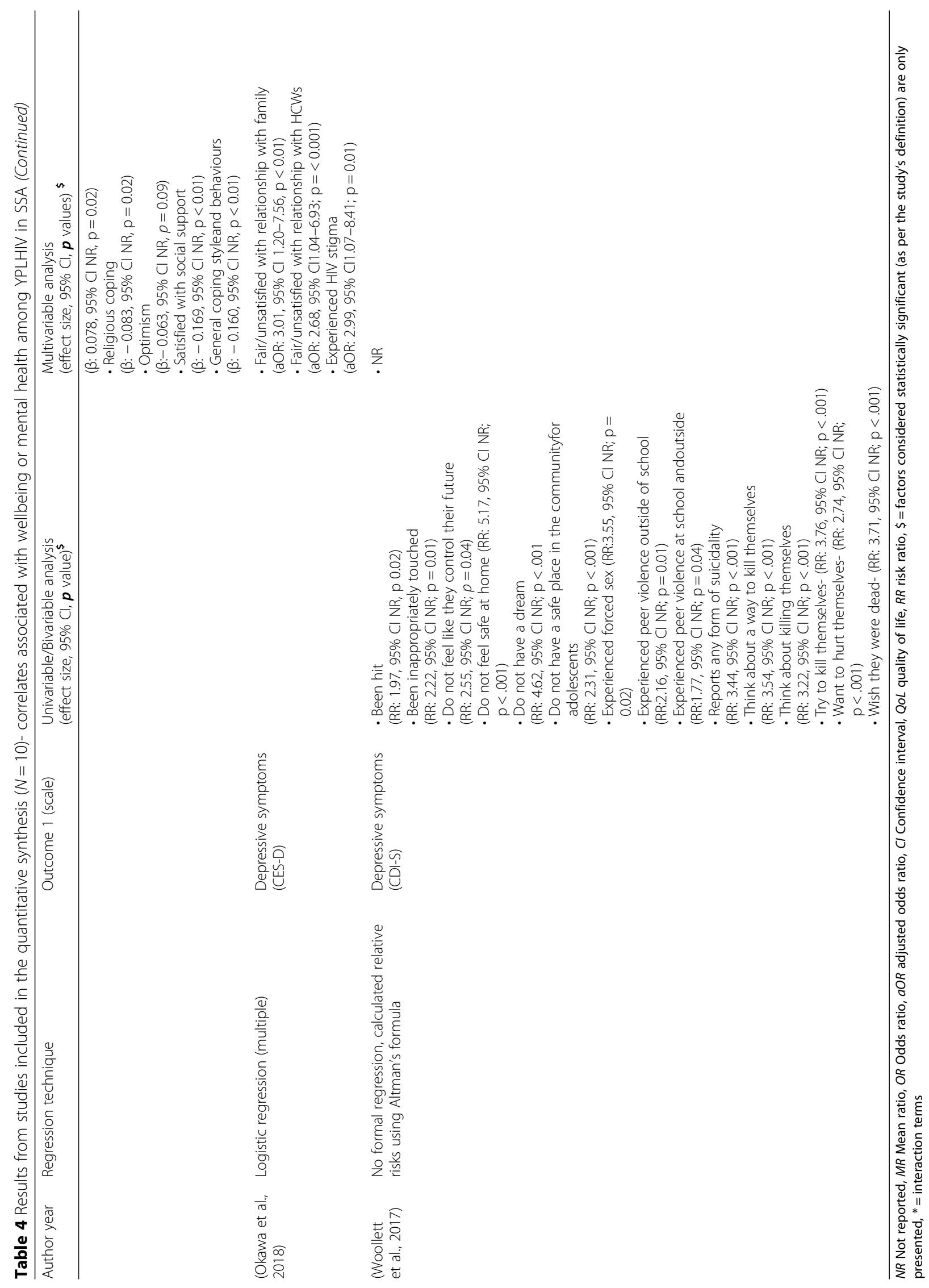


Table 5 Quality assessment of studies included in the quantitative synthesis $(N=10)$. These studies examined correlates of wellbeing or mental health among YPLHIV in SSA \$

\begin{tabular}{|c|c|c|c|c|c|c|c|c|c|}
\hline \multirow[t]{2}{*}{ Author year } & \multicolumn{2}{|c|}{ Sampling (max score 4) } & \multicolumn{2}{|c|}{ Measurement (max score 8) } & \multicolumn{3}{|c|}{ Reporting (max score 8) } & \multirow{2}{*}{$\begin{array}{l}\text { Total score } \\
\text { Maximum } \\
\text { score }=20\end{array}$} & \multirow[t]{2}{*}{ Quality } \\
\hline & Generalisability & $\begin{array}{l}\text { Sample } \\
\text { size }\end{array}$ & $\begin{array}{l}\text { Psychometric } \\
\text { properties of } \\
\text { scale }\end{array}$ & $\begin{array}{l}\text { Scale } \\
\text { administration }\end{array}$ & $\begin{array}{l}\text { Description } \\
\text { of analysis }\end{array}$ & $\begin{array}{l}\text { Reporting of } \\
\text { regression } \\
\text { analysis }\end{array}$ & $\begin{array}{l}\text { Adjustment of } \\
\text { confounders }\end{array}$ & & \\
\hline $\begin{array}{l}\text { (Abebe } \\
\text { et al., 2019) }\end{array}$ & 1 & 2 & 1 & 3 & 1 & 3 & 1 & 12 & Medium \\
\hline $\begin{array}{l}\text { (Dow et al., } \\
\text { 2016) }\end{array}$ & 1 & 2 & 1 & 2 & 1 & 1 & 0 & 8 & Low \\
\hline $\begin{array}{l}\text { (Earnshaw } \\
\text { et al., 2018) }\end{array}$ & 1 & 1 & 0 & 1 & 2 & 3 & 1 & 9 & Low \\
\hline $\begin{array}{l}\text { (Gaitho } \\
\text { et al., 2018) }\end{array}$ & 1 & 1 & 0 & 1 & 1 & 4 & 2 & 10 & High \\
\hline $\begin{array}{l}\text { (Gentz et al., } \\
\text { 2017) }\end{array}$ & 1 & 0 & 1 & 2 & 0 & 1 & 2 & 7 & Low \\
\hline $\begin{array}{l}\text { (Kim et al., } \\
\text { 2015) }\end{array}$ & 1 & 2 & 3 & 2 & 2 & 3 & 2 & 15 & Medium \\
\hline $\begin{array}{l}\text { (Mbalinda } \\
\text { et al., 2015) }\end{array}$ & 1 & 2 & 2 & 1 & 1 & 3 & 2 & 12 & Medium \\
\hline $\begin{array}{l}\text { (Mutumba } \\
\text { et al., 2017) }\end{array}$ & 1 & 2 & 2 & 2 & 1 & 3 & 1 & 12 & Medium \\
\hline $\begin{array}{l}\text { (Okawa } \\
\text { et al., 2018) }\end{array}$ & 1 & 2 & 1 & 0 & 1 & 1 & 1 & 7 & Low \\
\hline $\begin{array}{l}\text { (Woollett } \\
\text { et al., 2017) }\end{array}$ & 1 & 2 & 1 & 1 & 0 & 0 & 0 & 5 & Low \\
\hline
\end{tabular}

$\$=$ The quality assessment tool that was applied was adapted from the Cochrane guidance on assessing risk of bias in non-randomised studies (Higgins and Green, 2011)

\section{Qualitative studies- characteristics and data synthesis}

Of the 30 qualitative studies (Table 3 ), most were undertaken in the eastern sub-region $(N=14)$ : Uganda $(n=$ $11)$, Kenya $(n=2)$, Tanzania $(n=1)$ and the southern sub-region $(N=14)$ (South Africa $(n=9)$, Namibia $(n=$ $1)$, Swaziland $(n=1)$, Zambia $(n=2)$, Zimbabwe $(n=1)$, with one study conducted in both regions (Tanzania and Botswana). The remaining study was conducted in West Africa (Nigeria $n=1$ ). Only six studies focused on a specific gender (females $n=5$, males $n=1$ ). Whilst none of the 30 studies specifically aimed to examine lived experiences of subjective or psychological wellbeing they did, however, explore experiences related to dimensions of PWB or mental health. The aim of most of the studies was to understand the psycho-social challenges experienced among YPLHIV. Five studies examined broader life experiences associated with wellbeing using ethnographic methods. Data were collected mainly via focusgroup discussions and in-depth interviews. Several studies included perspectives from caregivers $(n=9)$ and healthcare workers (HCWs) $(n=7)$, with only one study that included perspectives from educators.

\section{Specific analytical themes}

Three key themes emerged across all studies: 1) acceptance and belonging, 2) coping; 3) standard of living
(Table 6, Fig. 2). These themes shaped experiences suggestive of wellbeing as detailed below.

\section{i. Acceptance and belonging}

\section{a) HIV-related stigma and discrimination}

All the studies highlighted the role HIV-related stigma and discrimination played in reinforcing social isolation and poor mental health functioning among YPLHIV. Perceived contributors included forms of internalised stigma, characterised as fear of the rejection and isolation if HIV status was accidentally disclosed to peers [100], partners [101-104] or parents [103, 105, 106]. Hence, keeping one's HIV status undisclosed was often described as an everyday lived experience [107-110]. Studies described how internalised stigma impeded ability to build "healthy identities" [104, 108, 111] and access social support [101]. Gendered social expectations appeared to facilitate internalised stigma and consequently limited disclosure. For example, in Uganda, a young woman living with HIV feared loss of social value if her intimate relationship was curtailed and hence opted for non-disclosure of her HIV status [101]. Similarly, young 


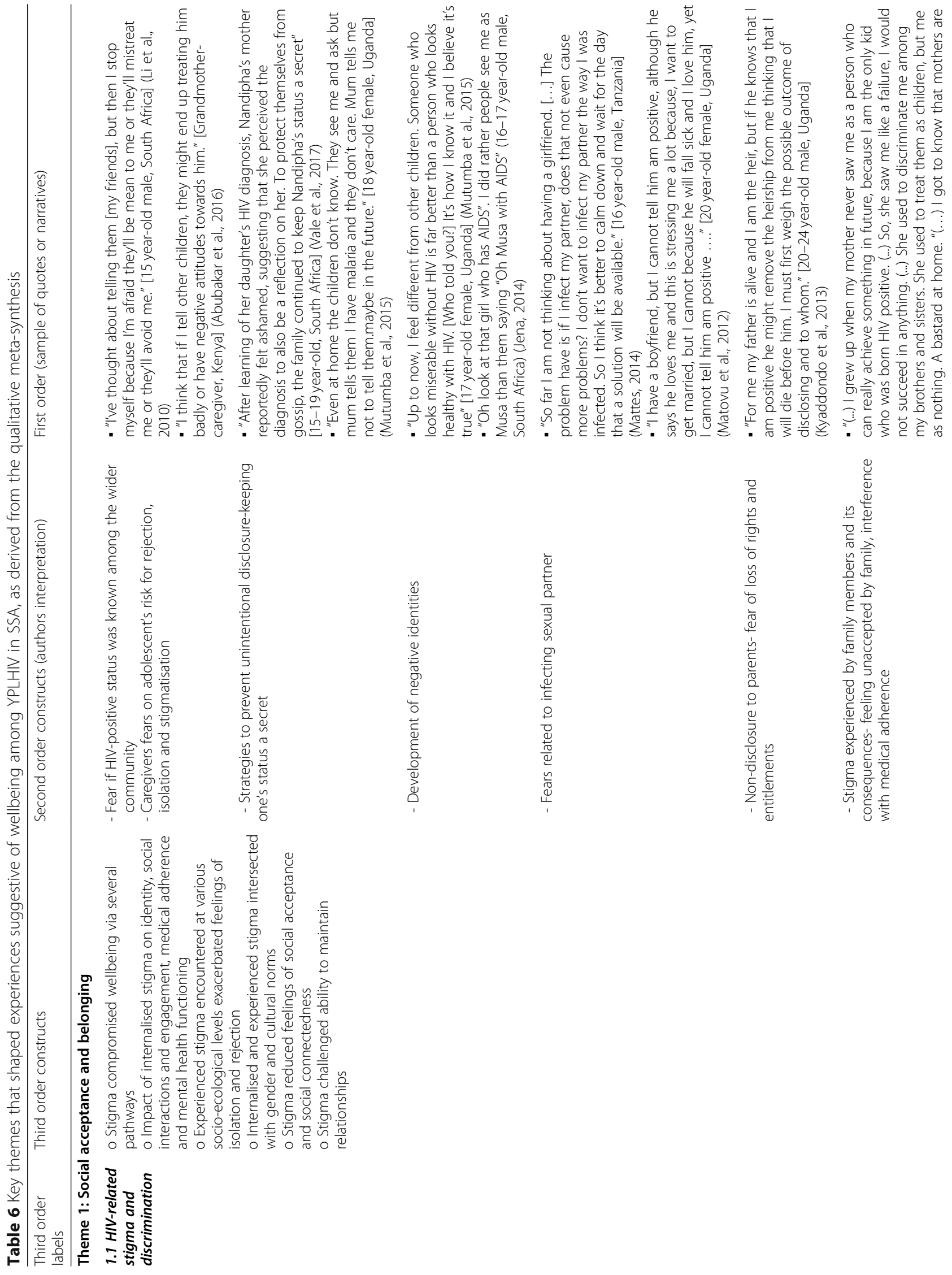




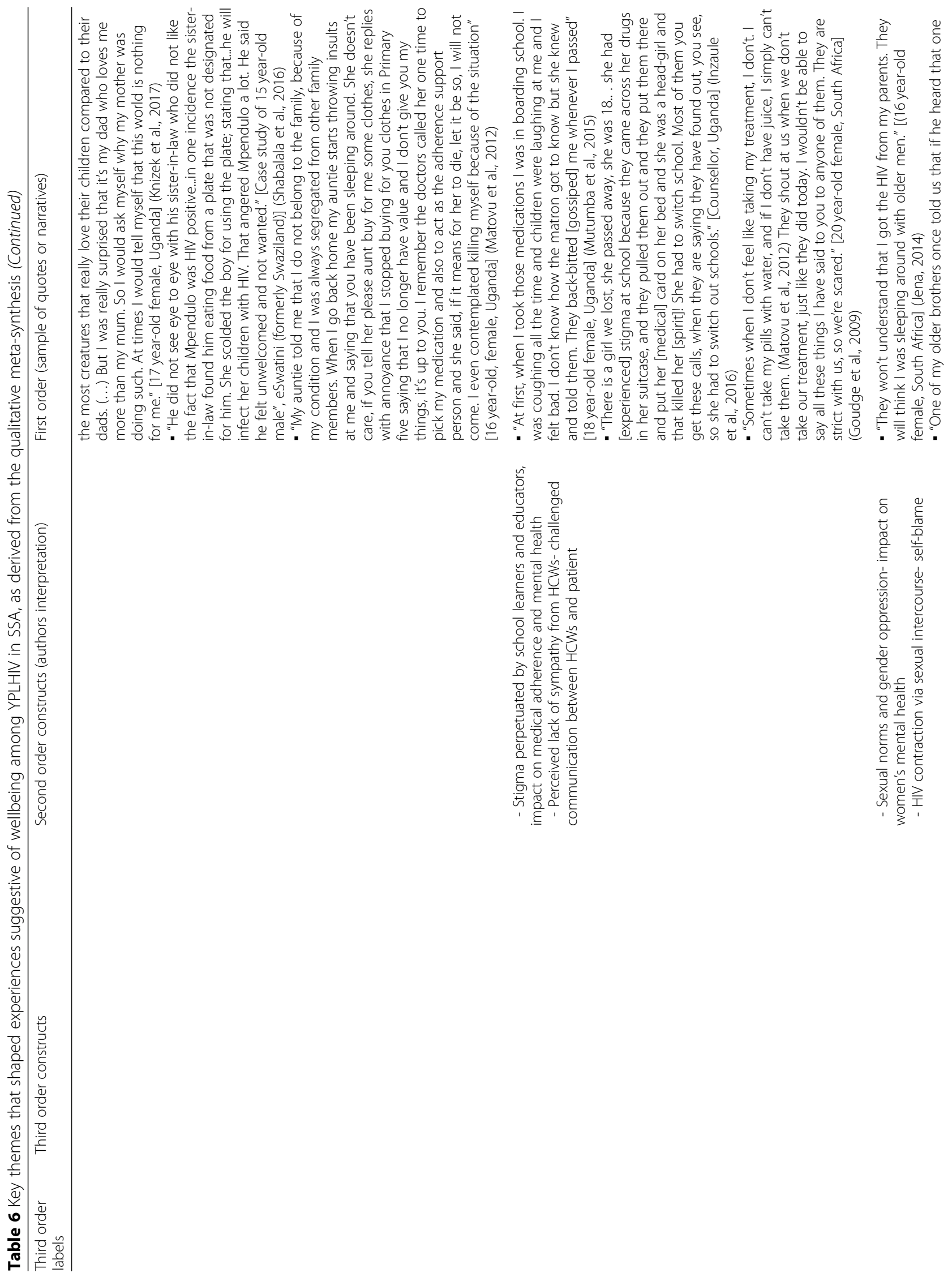




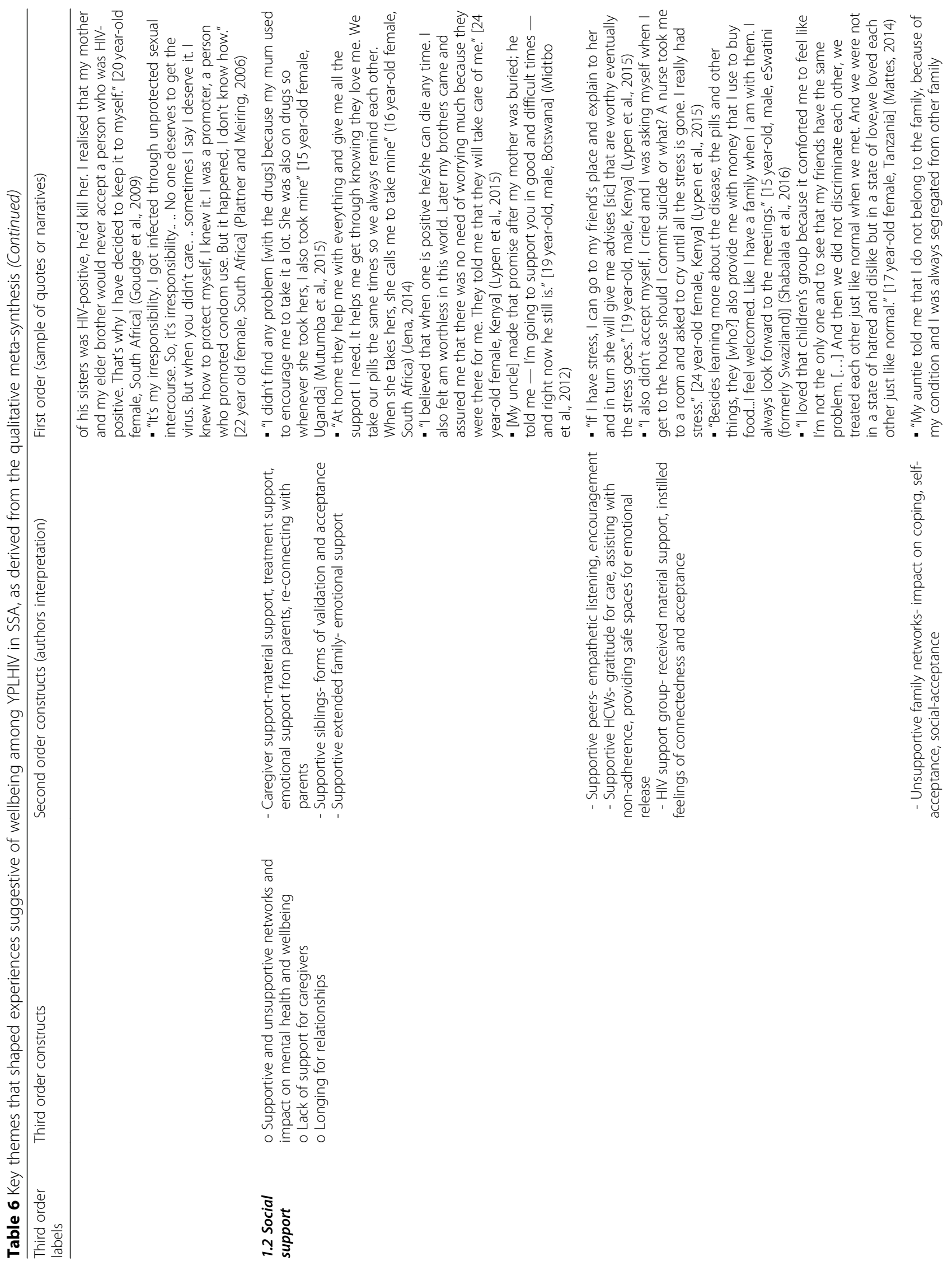




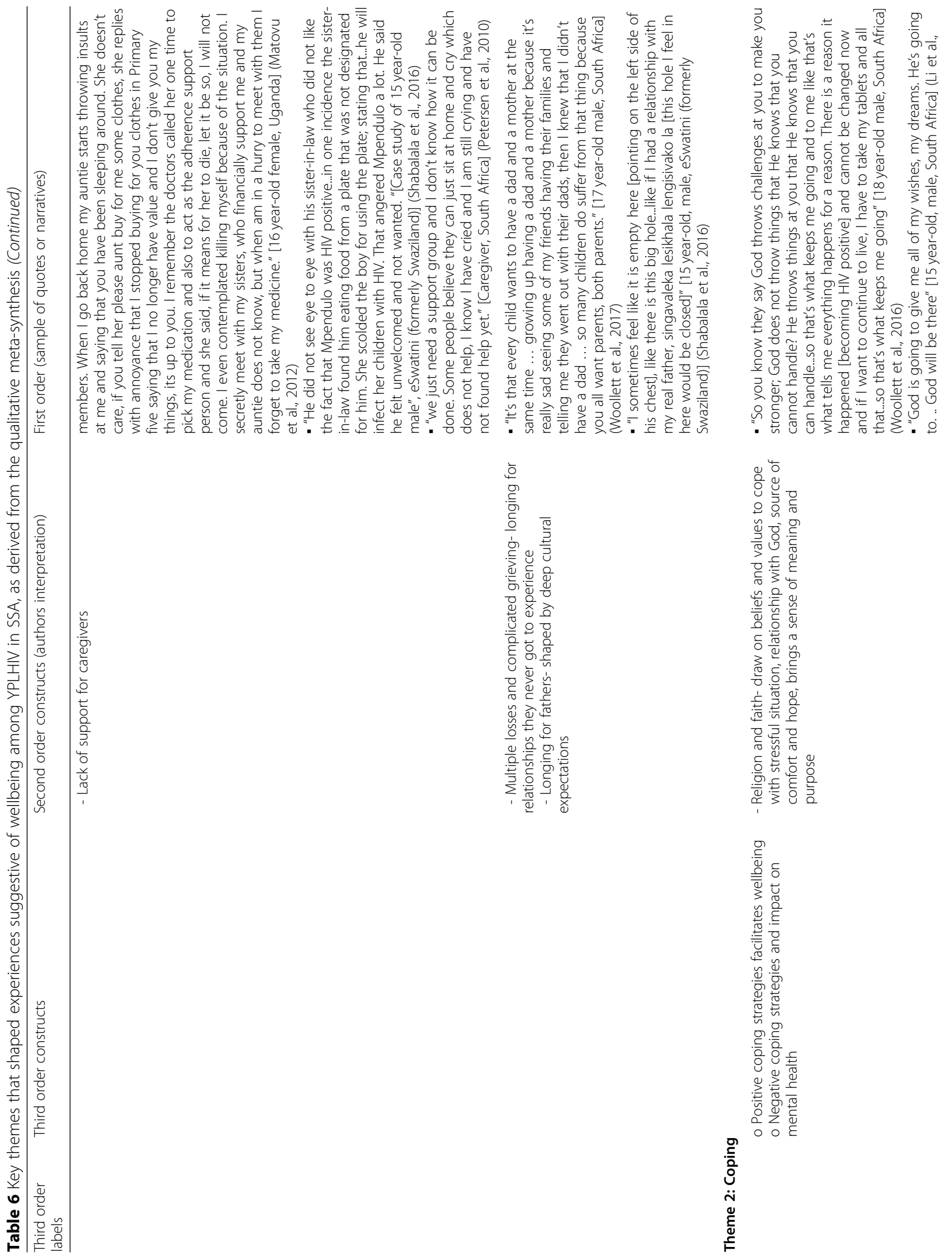




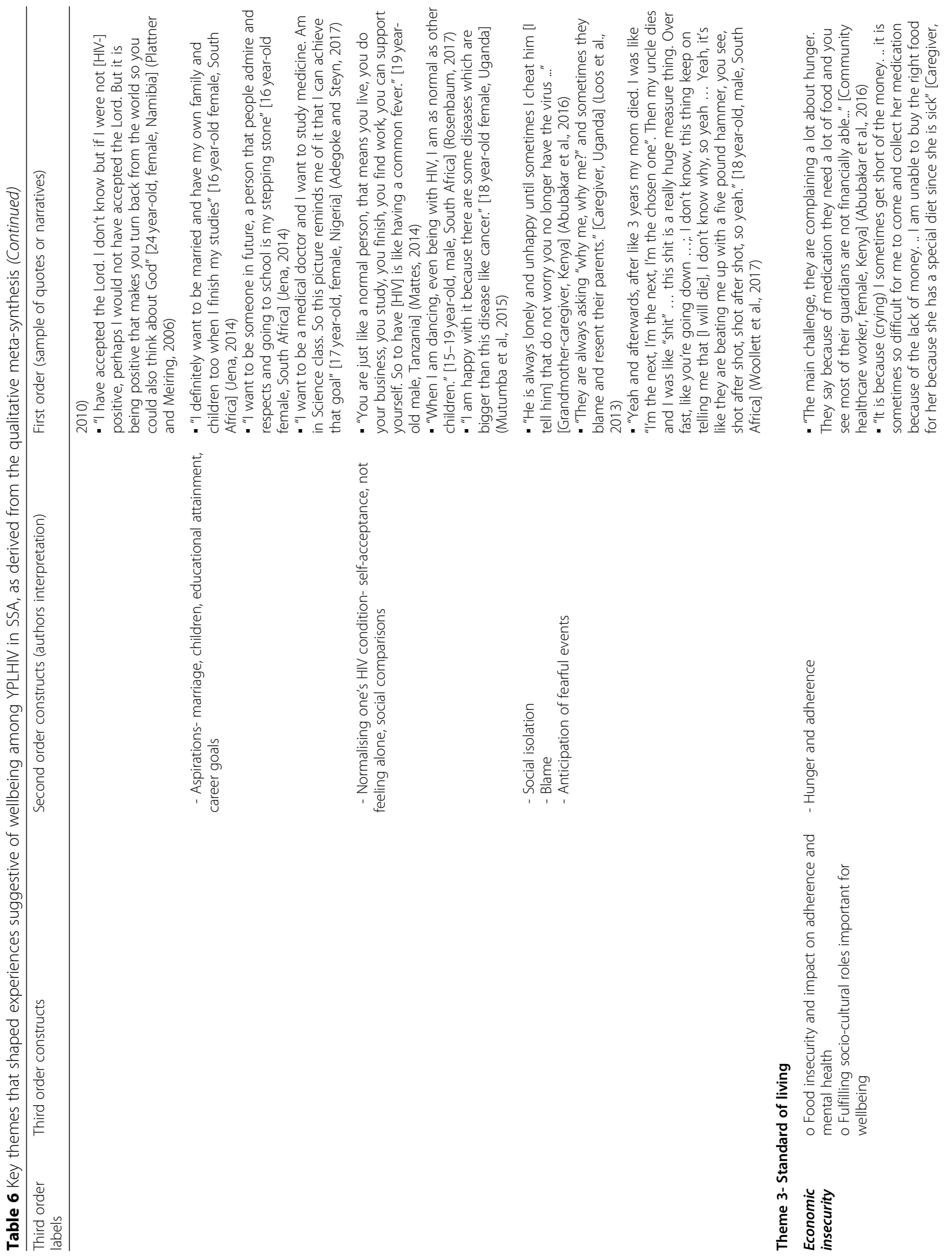




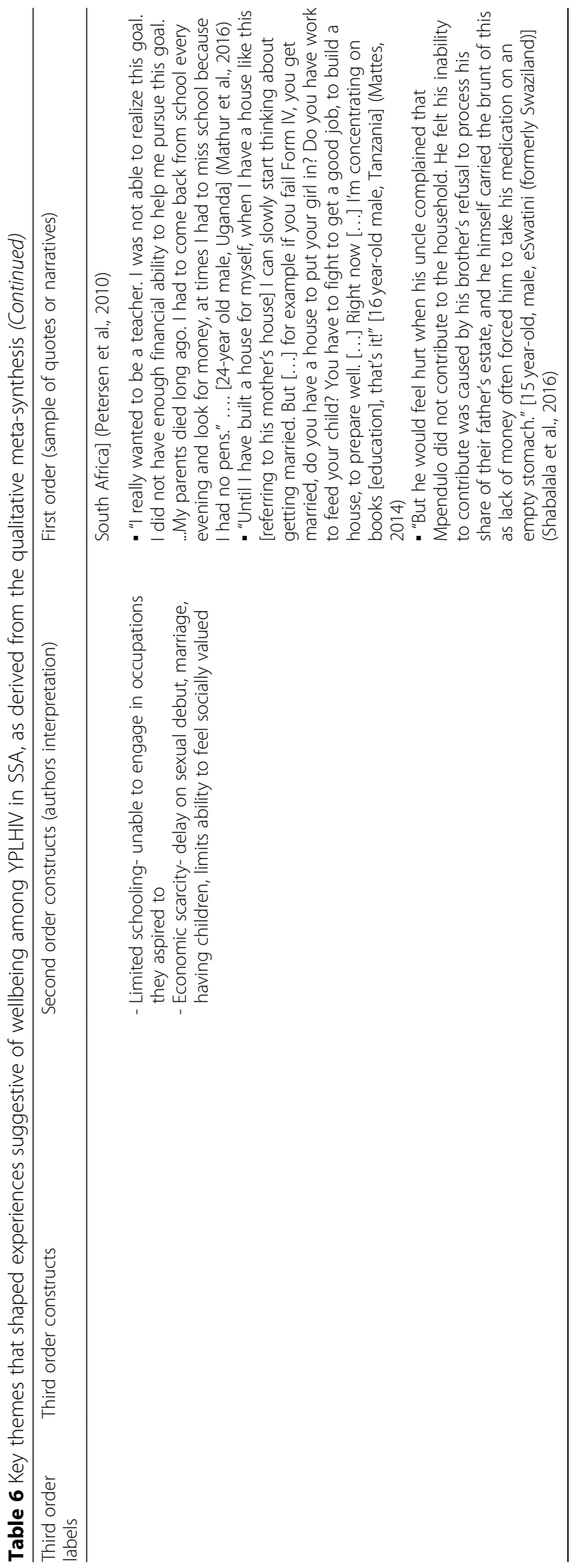




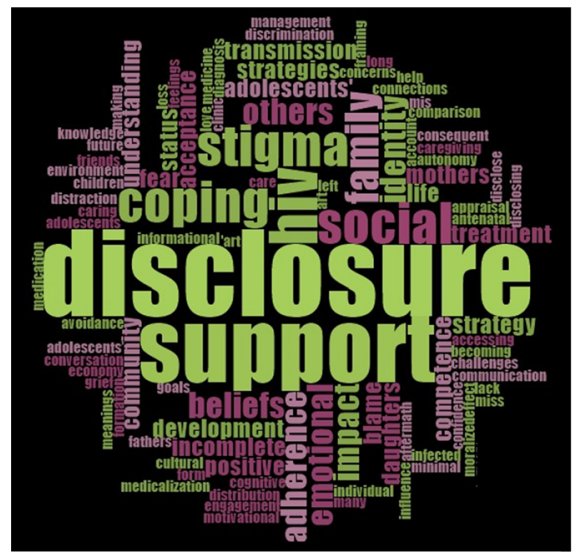

a) Females

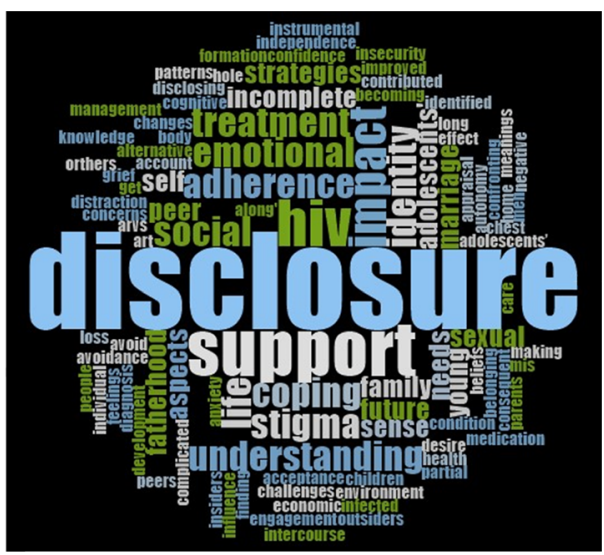

b) Males

Fig. 2 Words and phrases in themes used by authors of studies included in the qualitative synthesis. These studies examined lived experiences related to dimensions of wellbeing or mental health among YPLHIV in SSA. The text font size indicates frequency

men living with HIV in Uganda felt unable to uphold masculine socio-cultural identities and thus chose not to disclose their HIV status to their parents in fear of the "loss of rights" to endowments [105, 106]. Most studies described the manifestations of HIV-related stigma in terms of experienced stigma, which was encountered in relationships with mothers [112, 113], family members [101, 114], learners and educators (102Mutumba et al., 2015, 107, 115), and HCWs [115] [113]. Authors also described how stigma intersected with gendered attitudes towards sexuality and self-acceptance among young women [101, 115-117], including cultural norms such as respect for elders $[113,118,119]$.

\section{b) Social support}

The importance of relationships and social connections was expressed in several studies. Shabalala, De Lannoy [114] notes that for YPLHIV in eSwatini (formerly called Swaziland) strong relationships with caregivers were linked with "being accepted, being connected and welcomed". Mutumba, Bauermeister [102] describes how pill taking between HIV-positive parents and YPLHIV in Uganda fostered bonding "whenever she took hers, I also took mine". In contrast, in three studies, young women expressed the lack of support from caregivers [101, 112, 120]. Trusting relationships with family members were frequently described as important [101, 102, 109, 121, 122]. In a Kenyan study, authors indicate that the acceptance received from siblings served to "validate the participant as a human being" [109]. Unsupportive family networks were also described in the literature in the context of poor mental health functioning and reduced wellbeing (i.e. lack of selfacceptance) [101, 114].
Furthermore, studies described how YPLHIV drew on their friendship networks to manage treatment adherence, seek advice and feel accepted [104, 109, 123]. Several participants expressed gratitude for the informational and emotional support received from HCWs [107, 109, 119, 124]. Furthermore, in settings were YPLHIV had access to support groups, feeling "comforted" [103], "normal" [103] "welcomed" [114], "open to share" [121], and "not alone" [111] were dominant in the narratives. Caregivers in a South African study highlighted their lack of social support and how it hindered their ability to cope and subsequently support their children [104]. In three studies, YPLHIV articulated a deep longing for their deceased parents which authors indicated signified the importance parents played in nurturing belonging and its link with creating meaning in life [104, 114, 117, 120]. Moreover, the yearning for one's father was interpreted as being underpinned by "cultural expectations of being cared for and finding a rightful place in their father's home" [114].

\section{ii. Coping}

A key positive factor that YPLHIV utilised for coping was religion and faith, especially when support was limited. Religion and faith were primarily expressed as "belief in God" [100, 109, 111, 112, 116, 121, 123, 125]. Most authors perceived religion as bringing comfort and hope, as well as meaning and purpose in their lives. In addition, in a Namibian study, interpreting HIV acquisition as a "test or punishments from God" helped a young woman to accept her HIV status [116]. Another major positive coping strategy that YPLHIV applied was future goal setting such as desire for marriage and children [107, 119, 125, 126]. Educational aspirations were perceived as bringing a sense of purpose or social value 
to participants' lives [107, 122]. In contrast, YPLHIV also utilised negative coping strategies such as social withdrawal [107, 108, 111], self-blame [102, 123] and anticipation of death [103, 104, 117].

\section{iii. Standard of living}

Most YPLHIV resided in non-nuclear and skippedgeneration households that had encountered multiple losses. These households were often described by authors as lacking economic security and social protection. In Kenya, Zimbabwe and South Africa, caregivers and community HCWs reported how food insecurity challenged ART adherence and positive mental health functioning among YPLHIV [104, 110, 111, 127]. Young men living with HIV often reported difficulty in establishing economic security as the sole reason for delaying sexual debut, marriage and having children [100, 103, 126]. In Uganda, two studies noted how young men had "shattered dreams" [112] as household poverty traps prevented young men from completing their schooling, achieving their career aspirations and entering into the formal labour market. A young man's inability to contribute to his household made him feel "unwanted" and "hurt" [114].

\section{Quality of studies}

Twenty-seven out of 30 qualitative studies were of medium $(n=19)$ to high quality $(n=8)$ (Table 7$)$. The remaining three studies were of low quality largely due to insufficient information on the methods and participant sample, including lack of description in the analysis. For most studies included in this synthesis, findings were presented clearly with concrete detail and discussed in relation to other literature and theories.

Based on the CERQual assessment, we report moderate confidence in most themes (Table 8).

\section{Overall synthesis}

Both our quantitative and qualitative evidence suggest that social networks were at the core of wellbeing for YPLHIV, which supports a relational construct of wellbeing among YPLHIV. Drawing on the relationality meaning model [60], our findings suggest that social relationships were critical in fostering belongingness and connectedness. This in turn contributed to a sense of meaning in and to life, and ultimately wellbeing. In addition, socio-cultural norms and values were important to the wellbeing of YPLHIV, as these helped realise the meaning of and in life. In contrast, our synthesis also revealed that in certain instances, social networks and gender norms embedded within these networks compromised wellbeing. Based on our evidence, dimensions that potentially constitute wellbeing for YPLHIV can be mapped onto the following PWB dimensions: 1) selfacceptance - internalised stigma, externalised stigma, social acceptance; 2) belonging - family connectedness; 3) autonomy - disclosure, sexual intercourse; 4) positive relations - social support; 5) environmental mastery positive and negative coping; 6) purpose in life - religious activities, educational aspirations .

\section{Discussion}

Through this mixed method review we sought to identify key dimensions of wellbeing among YPLHIV in SSA by synthesising the evidence on correlates and experiences of wellbeing. The goal of this review was to inform wellbeing measurement selection for health economic surveys that seek to evaluate the impact of HIV policies on wellbeing. Findings from our review indicate that key dimensions which define wellbeing for this population include social support, family belonging, self-acceptance, coping and purpose. These results suggest that multidimensional wellbeing measures with a strong focus on social relationships may be appropriate for this setting.

Economic studies from high income settings have found robust positive associations between social ties (e.g. family, peers, neighbours) and SWB (life satisfaction, happiness) [128]. However, our findings suggest that social networks have both benefits and liabilities for wellbeing among YPLHIV in this setting, which is consistent with recent evidence that highlights the positive and negative relational mechanisms of social networks on SWB [129], particularly among adolescents [130]. Our quantitative synthesis showed a strong positive correlation between HIV-related stigma and poor mental functioning which may likely reduce overall wellbeing as shown in previous studies among adults living with HIV in SSA [131] and high income countries [132]. Drawing on our qualitative review findings together with the relational meaning model [60] and Goffman's accounts of stigma [133], internalised stigma may reduce wellbeing by lowering self-worth. In addition, externalised stigma encountered within social networks may reduce connectedness of self with family members and peers [102, $112,134]$. Together, these processes are likely to challenge self-acceptance. The effects of stigma on wellbeing are likely be more pronounced for sexually HIV-positive young women, who, due to the intersection of stigma with sexual norms, may harbour heightened feelings of shame and rejection [113, 116]. These findings suggest that wellbeing measures which focus on self-acceptance and self-worth may be appropriate for this population.

Our synthesis also highlighted the importance of social relationships in bringing meaning to life for YPLHIV. However, caregivers often limited the decision-making of YPLHIV with regards to disclosure [102] and sexual intercourse [119], which may have reduced the ability of 
Table 7 Quality appraisal ${ }^{\text {\$ }}$ of full-text studies included in the qualitative synthesis $(N=30)$. These studies examined lived experiences related to dimensions of wellbeing or mental health among YPLHIV in SSA

\begin{tabular}{|c|c|c|c|c|}
\hline \multicolumn{5}{|c|}{ Quality ranking: Red=low, Yellow=medium, Green=high } \\
\hline First author and date of pub & $\begin{array}{l}\text { Domain 1-Research team } \\
\text { and reflexivity }\end{array}$ & Domain 2-Study design & $\begin{array}{l}\text { Domain 3-Analysis and } \\
\text { findings }\end{array}$ & Overall quality \\
\hline (Abubakar et al., 2016) & & & & Low \\
\hline (Adegoke and Steyn, 2017) & & & & High \\
\hline (Bernays et al., 2017) & & & & High \\
\hline (Campbell et al., 2012) & & & & High \\
\hline $\begin{array}{l}\text { (Dusabe-Richards et al., } \\
\text { 2016) }\end{array}$ & & & & Medium \\
\hline (Goudge et al., 2009) & & & & High \\
\hline (Inzaule et al., 2016) & & & & Medium \\
\hline (Jena, 2014) & & & & Medium \\
\hline (Kajubi et al., 2016) & & & & High \\
\hline (Knizek et al., 2017) & & & & Medium \\
\hline (Kyaddondo et al., 2013) & & & & Low \\
\hline (Li et al., 2010) & & & & Medium \\
\hline (Loos et al., 2013) & & & & Medium \\
\hline (Lypen et al., 2015) & & & & Medium \\
\hline $\begin{array}{l}\text { (Mackworth-Young et al., } \\
\text { 2017) }\end{array}$ & & & & Medium \\
\hline (Mattes, 2014) & & & & High \\
\hline (Mathur et al., 2016) & & & & Medium \\
\hline (Matovu et al., 2012) & & & & Medium \\
\hline (Mburu et al., 2014) & & & & Medium \\
\hline (Midtbo et al., 2012) & & & & Medium \\
\hline (Mutumba et al., 2015) & & & & Medium \\
\hline (Petersen et al., 2010) & & & & Medium \\
\hline (Pienaar and Visser, 2012) & & & & Medium \\
\hline $\begin{array}{l}\text { (Plattner and Meiring, } \\
\text { 2006) }\end{array}$ & & & & Low \\
\hline (Rosenbaum, 2017) & & & & Medium \\
\hline (Shabalala et al., 2016) & & & & High \\
\hline (Siu et al., 2012) & & & & Medium \\
\hline (Vale et al., 2017) & & & & High \\
\hline (Woollett et al., 2016) & & & & Medium \\
\hline (Woollett et al., 2017) & & & & Medium \\
\hline
\end{tabular}

\$= The quality appraisal tool was adapted from the COREQ checklist (Tong et al., 2007) and informed by studies in this area (Tracy, 2010; Mays and Pope, 2000). 


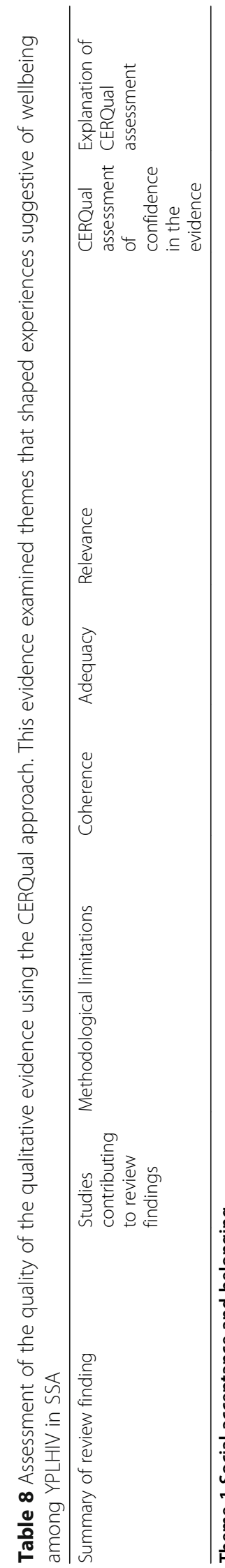

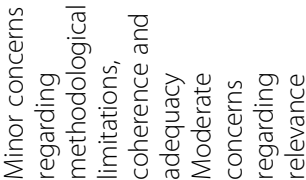

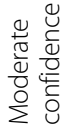

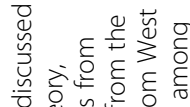

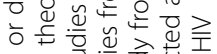

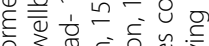

온

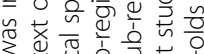

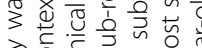

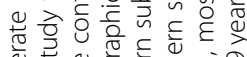

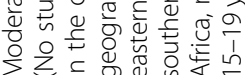

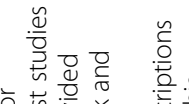

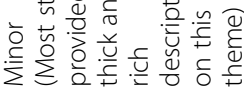

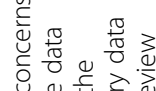

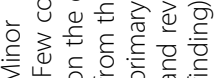

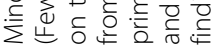

$\overline{\bar{\sigma}}$

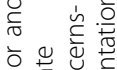

है

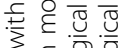

这势 응 응

to

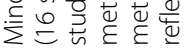

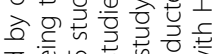

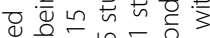

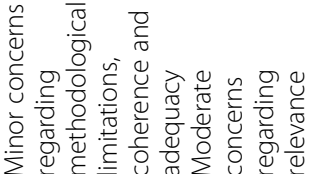

竞

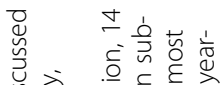

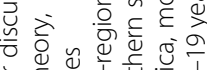

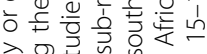

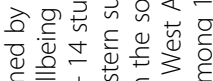

हो

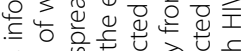

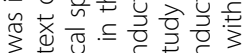

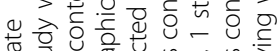

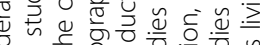

要

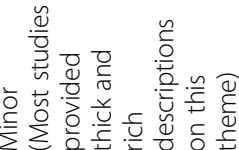

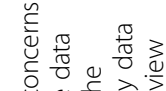

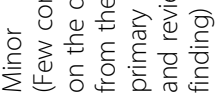

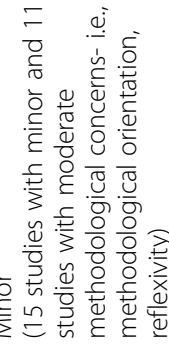

$\stackrel{\infty}{\sim}$

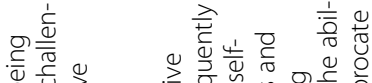

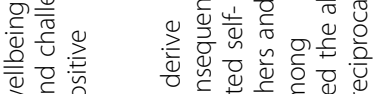

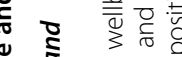

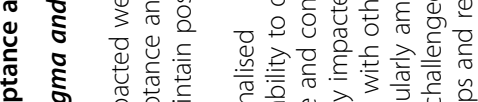

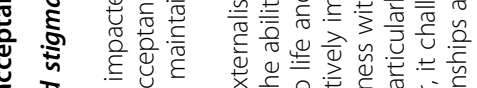

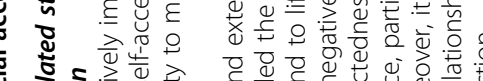

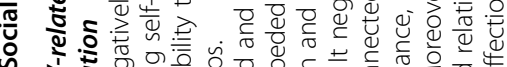

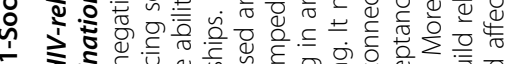

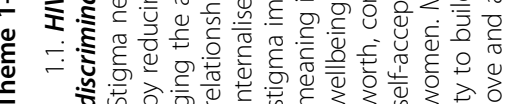

ڤั

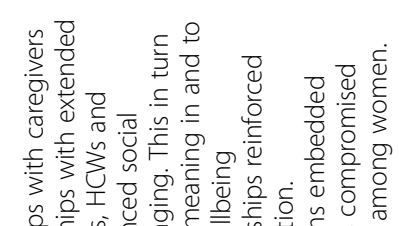

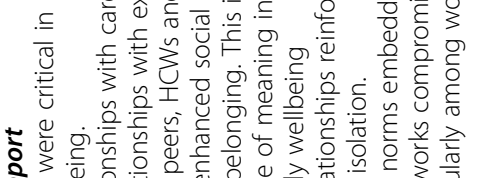

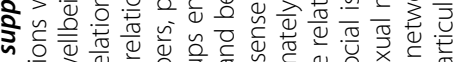

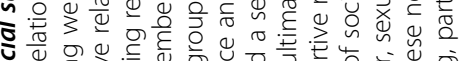

Q

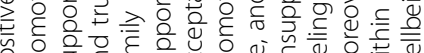

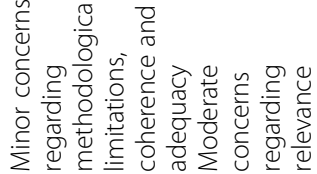

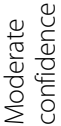

兽

읗

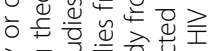

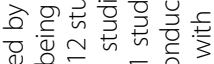

ह

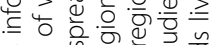

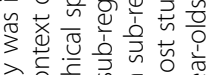

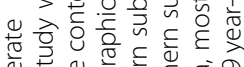

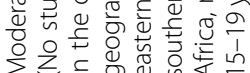

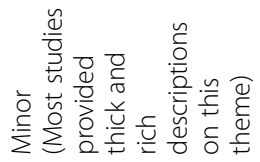

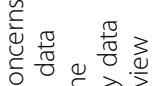

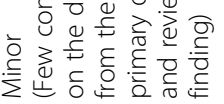

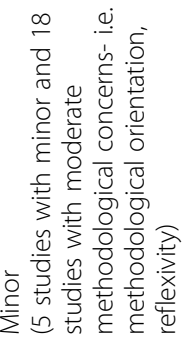

๗

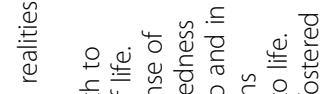

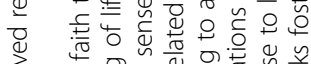

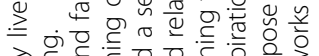

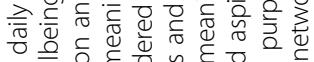

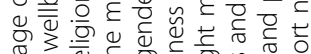
일

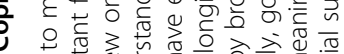
i 


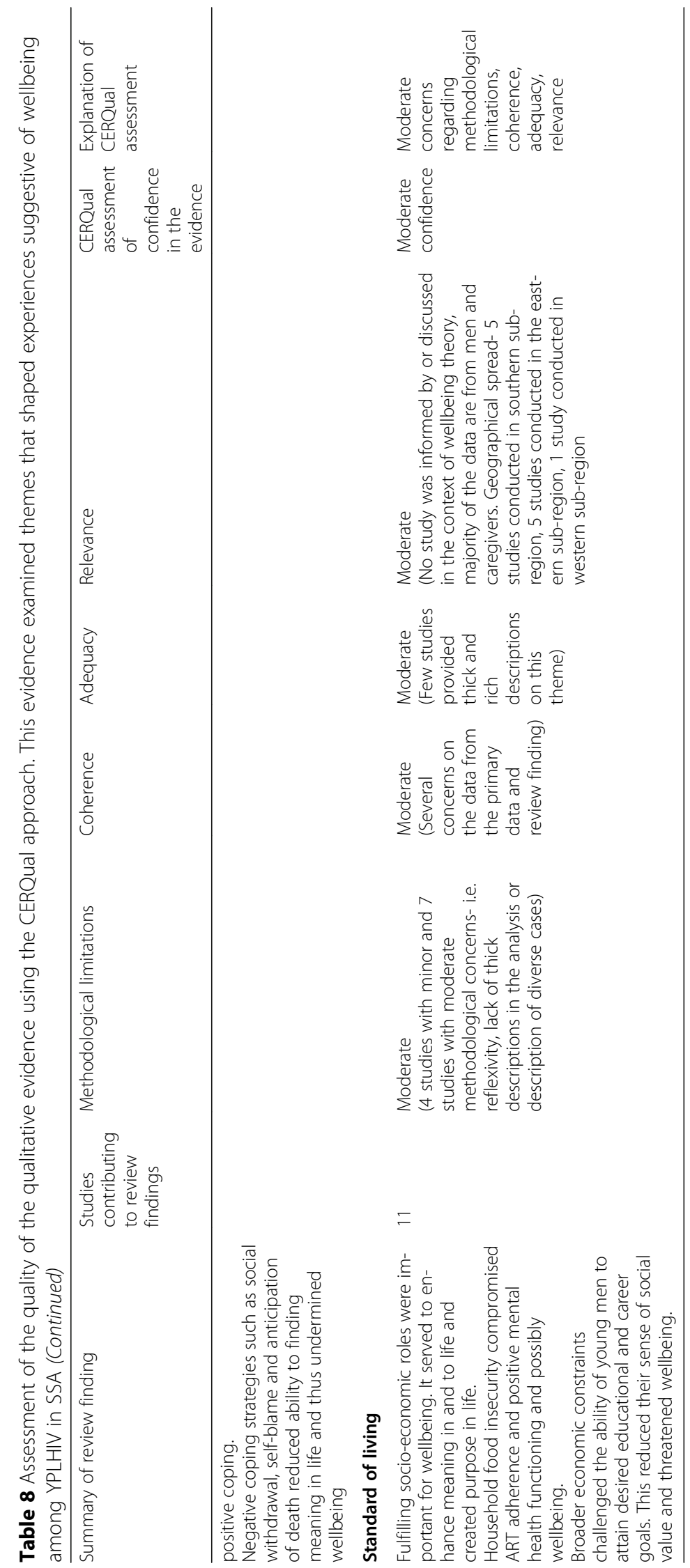


YPHIV to build relationships and reciprocate affection. In addition, the absence of relationships, particularly with fathers, may have reduced belongingness [114]. Family belonging has been shown to mediate pathways to SWB [135] and PWB [136] among adolescents in developed settings, possibly via promotion of meaning in life [137]. Overall, these findings highlight the relevance of selecting wellbeing measures with dimensions designed to capture family belongingness and autonomy.

Our review revealed a link between strong social support networks and positive mental health among YPLHIV. It is plausible that these strong social networks also promote PWB as shown in a previous adolescent study from Brazil [138]. Accounts from our qualitative synthesis suggest that YPLHIV drew on the emotional support from family, peers and HCWs members during challenging life events (i.e. disclosure, adherence challenges, rejection) which may have helped maintain positive mental health and potentially PWB [102, 103, 109]. However, in instances where supportive social networks were limited, we found that YPLHIV drew on negative coping mechanisms (e.g. social withdrawal, self-blame) [104], which likely reduced their PWB [139]. Our findings suggest that social support positively impacts PWB by adding meaning to life, specifically on an intrapersonal level such as improving one's sense of environmental mastery (e.g. ART adherence), a dimension of PWB. Our findings suggest that wellbeing measures should also encompass dimensions related to positive relations and environmental mastery.

Our review showed that socio-cultural values, norms and beliefs were critical for creating purpose in life among YPLHIV, which is also considered important for positive youth development [140]. Results from our qualitative synthesis suggest that religious beliefs, values and practices, helped YPLHIV understand the meaning of life, particularly in relation to their HIV status [116], which is agreement with previous adolescent studies $[100,125,141,142]$. Educational and employment aspirations were commonly reported in our qualitative evidence $[107,122,126]$, and may have helped promote wellbeing by creating a sense of purpose in life [43]. In addition, the desire for economic security among males $[103,114,126]$ also suggests that their wellbeing may be rooted in their ability to fulfil socio-cultural roles such as breadwinners, and thereby add purpose to their lives. These findings suggest that wellbeing measures that consider domains such religion living standards or dimensions such as purpose in life might be valuable for this population.

Overall, our findings support the use of multidimensional relational wellbeing scales aligned to life domains which are important to YPLHIV (i.e. family, religion, education, living standards). Subjective wellbeing scales that consider these domains include the Personal Wellbeing Index [42] and the Student Life Satisfaction Scale [41]. The Personal Wellbeing Index has been applied in South Africa's national social attitudes survey of individuals aged 16 years and older [143]. The Personal Wellbeing Index has exhibited good scale reliability among adolescents in developing countries [144] whereas the Student Life Satisfaction Scale has shown favourable psychometric properties among children in South Africa [145]. Broader wellbeing scales such as Ryff's PWB scale and the Mental Health Continuum Short- Form have shown strong alignment with themes that emerged in our synthesis (i.e. social support, belonging, purpose in life, self-acceptance). These PWB scales have shown good validity among adolescent populations in the North [146]. In addition, the Mental Health Continuum Short- Form has shown strong alignment with conceptualisation of a good life among adolescents in South Africa [65]. Further studies are needed to validate these wellbeing measures among YPLHIV in SSA, paying careful attention to translational issues [147, 148]. These proposed scales are relatively brief and can be either self- or interviewer- administered in national economic or HIV surveys, including programme evaluations. In addition, key dimensions of wellbeing in this setting (e.g. positive relations, acceptance, coping) could be used as key output measures in monitoring and evaluation frameworks of multi-sectoral HIV policies and programmes to indirectly assess wellbeing impacts. Our findings also highlight the importance of including social support, stigma, gender and living standards as explanatory variables in econometric models examining the wellbeing effects of HIV/AIDS policies among YPLHIV.

Key strengths of this review include: 1) use of mixedmethods, with qualitative data used to explain patterns in the quantitative synthesis; 2) use of a search strategy with a comprehensive definition of wellbeing that allowed us to examine wellbeing literature from multiple disciplines; 3) inclusion of both peer-reviewed articles and grey literature; 4) quality appraisal of each included study and quality assessment of the synthesised evidence.

This review is subject to the following limitations: 1) key population groups such as LGTBQI, sex workers and injecting drug users were excluded, as their lived experiences are likely to be different given the higher levels of stigma they possibly encounter relative to the general population of YPLHIV [149-151]; 2) several applicable regional conferences lack online abstract and thus our review may have missed potentially relevant material; 3) our review focused only on YPLHIV in SSA and thus findings may not be generalisable to other 
regions. However, results from recent studies suggest that there are similarities between YPLHIV in SSA and other developing nations within the SouthEast Asia Region and Region of the Americas in terms of correlates of mental illness [81, 152] and adherence $[153,154]$. Hence, results could be relevant to settings with similar disease and socioeconomic profiles. Several gaps in our evidence base were identified. First, no study directly assessed correlates of wellbeing (using a wellbeing scale) or evaluated experiences of subjective or psychological wellbeing. Second, there were no data from Central Africa, with only one study from West Africa. Third, our evidence is not generalisable to YPLHIV in the community given that most studies sampled individuals from healthcare facilities. Fourth, variability in outcome definition and scale choice made it difficult to compare between quantitative studies and did not allow for a meta-analysis. Fifth, the lack of age-stratified data limited our ability to compare correlates and wellbeing by relevant age-bands (1519 vs. 20-24 yrs.). Sixth, weaknesses in the study design and analytical techniques used in the quantitative evidence limited out ability to draw out any causal interpretations. Lastly, for the qualitative review, data saturation among 20-24-year-olds and YPLHIV in rural settings was not reached, leaving gaps in our understanding of how these factors may have shaped wellbeing.

\section{Conclusion}

The aim of this mixed-methods review was to identify dimensions of wellbeing among YPLHIV and measures that align to these dimensions for application in HIV policy evaluations. Understanding the wellbeing effects of HIV/AIDS policies could help steer policies in the direction that meets the broader needs of YPLHIV. This review has shown that social support was a key correlate of poor mental health and that social relationships shaped positive lived experiences. In view of the negative association between poor mental health functioning and measures of wellbeing found in the literature, it is plausible to posit that in this population wellbeing is multi-dimensional and that relational dimensions frame wellbeing among YPLHIV. Multi-dimensional wellbeing scales with a strong relational focus that could be applicable for this group include the Personal Wellbeing Index, Ryff's PWB and Mental Health Continuum Short-Form. Future studies should go beyond the investigation of mental health and examine wellbeing, based on definitions grounded in theory, to provide more accurate data on the wellbeing effects of policies. However, psychometric evaluations of these scales in this population in SSA are warranted, together with validation of these scales against adolescents and young people's subjective experiences in SSA.

\section{Supplementary information}

Supplementary information accompanies this paper at https://doi.org/10. 1186/s12955-020-01352-w.
Additional file 1. PRISMA Checklist.
Additional file 2. ENTREQ Checklist.
Additional file 3. Search strategy-MEDLINE (OVID).
Additional file 4. Search strategy- Psychlnfo (OVID).
Additional file 5. Search strategy- Econlit (OVID).
Additional file 6. Search strategy- AfricaWide (EMBASE).
Additional file 7. Search strategy- Web of Science.
Additional file 8. Search strategy- ProQuest.
Additional file 9. Search strategy- IAS conference abstract archive.
Additional file 10. Search strategy- Other databases.
Additional file 11. Table 4. Quantitative review outcomes- additional.

\section{Abbreviations}

AIDS: Acquired immune deficiency syndrome; ART: Antiretroviral therapy; HIV: Human immunodeficiency virus; LGTBQI : Lesbian, gay, bisexual, transgender, transsexual, queer, questioning, intersex, PWB: Psychological wellbeing; SDG: Sustainable Development Goals; SSA: Sub-Saharan Africa; SWB: Subjective wellbeing; WHO: World Health Organization; YPLHIV: Young people living with HIV

\section{Acknowledgements}

We thank the following colleagues who assisted in obtaining full texts of the articles (Sharleen Lategaan, Nothando Mhlongo), provided guidance on the methodology (Willem Odendaal) and commented on manuscript drafts (Willem Odendaal).

\section{Authors' contributions}

Darshini Govindasamy: Conceptualization, Methodology, Project administration, Software, Formal analysis, Investigation, Data Curation, Writing - Original, drafts, final. Janet Seeley: Supervision, Conceptualization, Methodology, Validation, Resources, Writing- critical review of all drafts. Ioana D Olaru: Data Curation, Writing- review of drafts, Alison Wiyeh: Data Curation, Writing- review of drafts, Catherine Mathews: Funding acquisition, Validation, Writing- review of drafts. Giulia Ferrari: Supervision, Validation, Conceptualization, Methodology, Resources, Writing- critical review of all drafts. The author(s) read and approved the final manuscript.

\section{Funding}

This study was funded by the South African Medical Research Council (Intramural grant- SAMRC-RFA-IRF-02-2016, Health Systems Research Unit Seed fund), and the National Research Foundation (Thuthuka grant-

TTK160504163987). DG, CM and AW are funded by the South African Medical Research Council. These funders had no role in the design, implementation, analysis and write-up of the study.

The Degree from which this study emanated was funded by the South African Medical Research Council through its Division of Research Capacity Development under the Bongani Mayosi National Health Scholarship Programme from funding received from the Public Health Enhancement Fund/South African National Department of Health. The content hereof is the sole responsibility of the authors and does not necessarily represent the official views of the SAMRC.

\section{Availability of data and materials}

The datasets used in the current study is available from the corresponding author on request.

\section{Ethics approval and consent to participate}

Ethics approval for this study was obtained from the ethics committees of the South African Medical Research (EC037-11/2016) and London School of Hygiene and Tropical Medicine (13782-1). 


\section{Competing interests}

None to declare.

\begin{abstract}
Author details
'Department of Global Health and Development, Faculty of Public Health and Policy, London School of Hygiene and Tropical Medicine, London, UK. ${ }^{2}$ Health Systems Research Unit, South African Medical Research Council, Francie van Zijl Drive, Parow Valley, PO Box 19070, Tygerberg 7501, South Africa. ${ }^{3}$ Adolescent Health Research Unit, Department of Child and Adolescent Psychiatry, University of Cape Town, Cape Town, South Africa. ${ }^{4}$ Department of Clinical Research, Faculty of Infectious and Tropical Diseases, London School of Hygiene and Tropical Medicine, London, UK. ${ }^{5}$ Biomedical Research and Training Institute, Harare, Zimbabwe. ${ }^{6}$ Cochrane South Africa, South African Medical Research Council, Tygerberg, South Africa. ${ }^{7}$ Department of Epidemiology, University of Washington School of Public Health, Seattle, Washington, USA.
\end{abstract}

Received: 26 November 2019 Accepted: 3 April 2020

Published online: 05 May 2020

\section{References}

1. World Bank. World Development Report 2007 [Available from: http://web. worldbank.org/WBSITE/EXTERNAL/EXTDEC/EXTRESEARCH/EXTWDRS/ 0, contentMDK:23062361 pagePK:478093 piPK:477627 theSitePK:477624,00. html.

2. Layard R, Clark AE, Cornaglia F, Powdthavee N, Vernoit J. What predicts a successful life? A life-course model of well-being. Econ J. 2014;124(580):72038.

3. Bundy DAP, de Silva N, Horton S, Patton GC, Schultz L, Jamison DT. Investment in child and adolescent health and development: key messages from disease control priorities, 3rd edition. Lancet. 2018;391(10121):687-99.

4. Joint United Nations Programme on HIV and AIDS (UNAIDS). AIDSInfo 2019 [Available from: http://aidsinfo.unaids.org/.

5. Joint United Nations Programme on HIV/AIDS (UNAIDS). UNAIDS Data 2017 2017 [Available from: http://www.unaids.org/sites/default/files/media_ asset/20170720_Data_book_2017_en.pdf.

6. Lowenthal ED, Bakeera-Kitaka S, Marukutira T, Chapman J, Goldrath K, Ferrand RA. Perinatally acquired HIV infection in adolescents from subSaharan Africa: a review of emerging challenges. Lancet Infect Dis. 2014; 14(7):627-39.

7. Bernays $S$, Jarrett $P$, Kranzer $K$, Ferrand RA. Children growing up with HIV infection: the responsibility of success. Lancet. 2014:383(9925):1355-7.

8. Kagee A, Coetzee B, Toit SD, Loades ME. Psychosocial predictors of quality of life among South Africa adolescents receiving antiretroviral therapy. Qual Life Res. 2018;28:57-65.

9. Ferrand $\mathrm{R}$, Lowe $\mathrm{S}$, Whande $\mathrm{B}$, Munaiwa $\mathrm{L}$, Langhaug $\mathrm{L}$, Cowan $\mathrm{F}$, et al. Survey of children accessing HIV services in a high prevalence setting: time for adolescents to count? Bull World Health Organ. 2010;88(6):428-34.

10. United Nations (UN). Population 2030- Demographic challenges and opportunities for sustainable development planning 2015 [Available from: http://www.un.org/en/development/desa/population/publications/pdf/ trends/Population2030.pdf.

11. Bloom DE, Kuhn M, Prettner K. Africa's prospects for enjoying a demographic dividend. J Demographic Economics. 2017;83(1):63-76.

12. Adler A, Seligman ME. Using wellbeing for public policy: theory, measurement, and recommendations. Int J Wellbeing. 2016;6(1):1-35.

13. Diener E, Eunkook SM, Richard LE, Heidi SL. Subjective well-being: three decades of progress. Psychol Bull. 1999;125(2):276-302.

14. Ryan RM, Deci EL. On happiness and human potentials: a review of research on hedonic and eudaimonic well-being. Annu Rev Psychol. 2001;52(1):14166.

15. Ryff CD. Happiness is everything, or is it? Explorations on the meaning of psychological well-being. J Pers Soc Psychol. 1989:57(6):1069-81.

16. Skovdal M, Belton S. The social determinants of health as they relate to children and youth growing up with HIV infection in sub-Saharan Africa. Child Youth Serv Rev. 2014:45:1-8.

17. West N, Schwartz S, Mudavanhu M, Hanrahan C, France H, Nel J, et al. Mental health in south African adolescents living with HIV. AIDS Care. 2019; 31(1):117-24.

18. Sherr L, Cluver LD, Toska E, He E. Differing psychological vulnerabilities among behaviourally and perinatally HIV infected adolescents in South
Africa - implications for targeted health service provision. AIDS Care. 2018, 30(sup2):92-101.

19. Kemigisha E, Zanoni B, Bruce K, Menjivar R, Kadengye D, Atwine D, et al Prevalence of depressive symptoms and associated factors among adolescents living with HIV/AIDS in South Western Uganda. AIDS Care. 2019:31:1297-303.

20. Casale M, Boyes M, Pantelic M, Toska E, Cluver L. Suicidal thoughts and behaviour among south African adolescents living with HIV: can social support buffer the impact of stigma? J Affect Disord. 2019;245:82-90.

21. Layard R, Chisholm D, Patel V, Saxena S. Mental illness and unhappiness 2013 [Available from: https://melbourneinstitute.unimelb.edu.au/assets/ documents/hilda-bibliography/working-discussion-research-papers/2013/ Layard etal Mental IIIness and Unhappiness dp7620.pdf.

22. Frijters $P$, Johnston DW, Shields MA. Destined for (un) happiness: does childhood predict adult life satisfaction? 2011 [Available from: http://anonftp.iza.org/dp5819.pdf.

23. Lundborg P, Nilsson A, Rooth D-O. Adolescent health and adult labor market outcomes. J Health Econ. 2014;37:25-40.

24. Fletcher J. Adolescent depression and adult labor market outcomes. Southern Econ J. 2013;80(1):26-49.

25. Healey A, Knapp M, Farrington DP. Adult labour market implications of antisocial behaviour in childhood and adolescence: findings from a UK longitudinal study. Appl Econ. 2004;36(2):93-105.

26. Fortson JG. Mortality risk and human capital investment: the impact of HIV/ AIDS in sub-Saharan Africa. Rev Econ Stat. 2011;93(1):1-15.

27. Akbulut-Yuksel M, Turan B. Left behind: intergenerational transmission of human capital in the midst of HIV/AIDS. J Population Econ. 2013;26(4):1523-47.

28. Lindert J, Bain PA, Kubzansky LD, Stein C. Well-being measurement and the WHO health policy health 2010: systematic review of measurement scales. Eur J Pub Health. 2015:25(4):731-40.

29. Kobau R, Sniezek J, Zack MM, Lucas RE, Burns A. Well-being assessment: an evaluation of well-being scales for public health and population estimates of well-being among US adults. Applied Psychology: Health and Well-Being. 2010:2(3):272-97.

30. Joint United Nations Programme on HIV/AIDS (UNAIDS), United Nations Children's Fund (UNICEF). A progress report: All in to end the adolescent HIV epidemic 2016 [Available from: http://www.unaids.org/sites/default/files/ media asset/ALLIN2016ProgressReport_en.pdf.

31. United Nations. World Youth Report-Youth and the 2030 Agenda for Sustainable Development 2018 [Available from: https://www.un.org/ development/desa/youth/wp-content/uploads/sites/21/2018/12/ WorldYouthReport-2030Agenda.pdf.

32. Lazarus JV, Safreed-Harmon K, Barton SE, Costagliola D, Dedes N, del Amo $\mathrm{VJ}$, et al. Beyond viral suppression of HIV-the new quality of life frontier. BMC Med. 2016:14(1):1-5.

33. Seckinelgin $\mathrm{H}$. HIV care cascade and sustainable wellbeing of people living with HIV in context. J Int AIDS Soc. 2019:22(2):1-2.

34. Saul J, Bachman G, Allen S, Toiv NF, Cooney C, Beamon TA. The DREAMS core package of interventions: a comprehensive approach to preventing HIV among adolescent girls and young women. PLoS One. 2018;13:12.

35. Stiglitz JE, Sen A, Fitoussi J-P. Report by the Commission on the Measurement of Economic Performance and Social Progress 2009 [Available from: http://www.communityindicators.net/publications/show/9.

36. Greco G, Lorgelly P, Yamabhai I. Outcomes in economic evaluations of public health interventions in low-and middle-income countries: health, capabilities and subjective wellbeing. Health Econ. 2016;25(S1):83-94.

37. Fan W, Bloom DE, Ogbuoji O, Prettner K, Yamey G. Valuing health as development: going beyond gross domestic product. Br Med J. 2018;363:1-5

38. Frey BS. What are the opportunities for future happiness research? Int Rev Econ. 2019:1-8.

39. Peasgood T, Bhardwaj A, Biggs K, Brazier JE, Coghill D, Cooper CL, et al. The impact of ADHD on the health and well-being of ADHD children and their siblings. Eur Child Adolesc Psychiatry. 2016;25(11):1217-31.

40. Powdthavee $\mathrm{N}$, Vignoles $\mathrm{A}$. Mental health of parents and life satisfaction of children: a within-family analysis of intergenerational transmission of wellbeing. Soc Indic Res. 2008;88(3):397-422.

41. Huebner ES. Initial development of the student's life satisfaction scale. Sch Psychol Int. 1991;12(3):231-40.

42. Cummins RA, Lau AL. Personal wellbeing index-school children (PWI-SC) (3rd Edition) 2005 [Available from: http://www.deakin.edu.au/research/ acqol/instruments/wellbeing_index.htm. 
43. Ryff CD. Psychological well-being revisited: advances in the science and practice of eudaimonia. Psychother Psychosom. 2014;83(1):10-28.

44. Keyes CLM. Brief description of the mental health continuum short form (MHC-SF) 2009 [Available from: https://www.aacu.org/sites/default/files/ MHC-SFEnglish.pdf.

45. Garvie P, Lawford J, Banet M, West R. Quality of life measurement in paediatric and adolescent populations with HIV: a review of the literature. Child Care Health Dev. 2009;35(4):440-53.

46. Chitah M, Jonsson D, Seshamani V. Investigating the health related quality of life of Zambian children living with HIV/AIDS on antiretroviral therapy. Health Econ Outcome Res Open Access. 2016;2(120):2.

47. Masquillier C, Wouters E, Loos J, Nöstlinger C. Measuring health-related quality of life of HIV-positive adolescents in resource-constrained settings. PLoS One. 2012;7(7):e40628.

48. Enimil A, Nugent N, Amoah C, Norman B, Antwi S, Ocran J, et al. Quality of life among Ghanaian adolescents living with perinatally acquired HIV: a mixed methods study. AIDS Care. 2016;28(4):460-4.

49. Govender K, Bhana A, McMurray K, Kelly J, Theron L, Meyer-Weitz A, et al. A systematic review of the south African work on the well-being of young people (2000-2016). S Afr J Psychol. 2018;49:52-69.

50. Ushie BA, Udoh EE. Where are we with Young People's wellbeing? Evidence from Nigerian demographic and health surveys 2003-2013. Soc Indic Res. 2016;129(2):803-33.

51. Pearson A, White H, Bath-Hextall F, Salmond S, Apostolo J, Kirkpatrick P. A mixed-methods approach to systematic reviews. Int J Evidence-Based Healthcare. 2015;13(3):121-31.

52. Oliver S, Harden A, Rees R, Shepherd J, Brunton G, Garcia J, et al. An emerging framework for including different types of evidence in systematic reviews for public policy. Evaluation. 2005;11(4):428-46.

53. Ben-Arieh A, Frønes I. Taxonomy for child well-being indicators: a framework for the analysis of the well-being of children. Childhood. 2011; 18(4):460-76.

54. Moher D, Shamseer L, Clarke M, Ghersi D, Liberati A, Petticrew M, et al. Preferred reporting items for systematic review and meta-analysis protocols (PRISMA-P) 2015 statement. Syst Rev. 2015;4(1):1.

55. Tong A, Flemming K, Mclnnes E, Oliver S, Craig J. Enhancing transparency in reporting the synthesis of qualitative research: ENTREQ. BMC Med Res Methodol. 2012;12(1):181.

56. Joanna Briggs Institute. Methodology for JBI mixed methods systematic reviews 2014 [Available from: https://nursing.lsuhsc.edu/JBI/docs/ ReviewersManuals/Mixed-Methods.pdf.

57. Delle Fave A, Brdar I, Wissing MP, Araujo U, Castro Solano A, Freire T, et al. Lay definitions of happiness across nations: the primacy of inner harmony and relational connectedness. Front Psychol. 2016;7:1-23.

58. White SC, Jha S. Towards an interdisciplinary approach to wellbeing: life histories and self-determination theory in rural Zambia. Soc Sci Med. 2018; 212:153-60.

59. Gough I, McGregor JA, Camfield L. Theorising wellbeing in international development. In: Gough I, McGregor JA, editors. Wellbeing in developing countries: from theory to research. Cambridge: Cambridge University Press; 2007. p. 3-44.

60. Wissing MP. Meaning and relational well-being: a reflection on the state of the art and a way forward. J Psychol Afr. 2014;24(1):115-21.

61. Krok D. When is meaning in life Most beneficial to Young people? Styles of meaning in life and well-being among late adolescents. J Adult Dev. 2018; 25(2):96-106.

62. Crivello G, Camfield L, Woodhead M. How can children tell us about their wellbeing? Exploring the potential of participatory research approaches within Young lives. Soc Indic Res. 2008;90(1):51-72.

63. Camfield $L$, Tafere $Y$. 'No, living well does not mean being rich': diverse understandings of well-being among 11-13-year-old children in three Ethiopian communities. J Children Poverty. 2009;15(2):119-38.

64. Geldenhuys $\mathrm{O}$. Relational well-being of a group of adolescents in a south African high-risk community. Potchefstroom: North-West University, South Africa; 2016.

65. Van Schalkwyk I, Wissing MP. Psychosocial well-being in a group of south African adolescents. J Psychol Afr. 2010;20(1):53-60.

66. Sandelowski M, Voils Cl, Barroso J. Defining and designing mixed research synthesis studies. Res Sch. 2006;13(1):1-15.

67. Higgins JP. Green S. Chichester John Wiley \& Sons: Cochrane Handbook for Systematic Reviews of Interventions; 2011.
68. Noblit GW, Hare RD. Meta-ethnography: synthesizing qualitative studies. Newbury Park, California: SAGE Publications; 1988.

69. Joint United Nations Programme on HIV/AIDS (UNAIDS). Get on the fasttrack. A life-cycle approach to HIV. Finding solutions for everyone at every stage of life 2016 [Available from: http://www.unaids.org/sites/default/files/ media_asset/Get-on-the-Fast-Track_en.pdf.

70. Kassebaum N, Kyu HH, Zoeckler L, Olsen HE, Thomas K, Pinho C, et al. Child and adolescent health from 1990 to 2015: findings from the global burden of diseases, injuries, and risk factors 2015 study. J Am Med Association Pediatrics. 2017:171:573-92.

71. Patton GC, Coffey C, Sawyer SM, Viner RM, Haller DM, Bose K, et al. Global patterns of mortality in young people: a systematic analysis of population health data. Lancet. 2009;374(9693):881-92.

72. Ryff CD, Keyes CLM. The structure of psychological well-being revisited. J Pers Soc Psychol. 1995;69(4):719-27.

73. Lombardo P, Jones W, Wang L, Shen X, Goldner EM. The fundamental association between mental health and life satisfaction: results from successive waves of a Canadian national survey. BMC Public Health. 2018; 18(1):1-9.

74. Patel V, Flisher AJ, Hetrick S, McGorry P. Mental health of young people: a global public-health challenge. Lancet. 2007;369(9569):1302-13.

75. Westerhof GJ, Keyes CLM. Mental illness and mental health: the two continua model across the lifespan. J Adult Dev. 2010;17(2):110-9.

76. World Bank. World Bank country and lending groups 2020 [Available from: https://datahelpdesk.worldbank.org/knowledgebase/articles/906519-worldbank-country-and-lending-groups.

77. Joint United Nations Programme on HIV and AIDS (UNAIDS). UNAIDS Gap Report Geneva, Switzerland: UNAIDS; 2014 [Available from: http://www. unaids.org/en/resources/campaigns/2014/2014gapreport/gapreport.

78. Joint United Nations Programme on HIV/AIDS (UNAIDS). UNAIDS Data 2018 2018 [Available from: http://www.unaids.org/sites/default/files/media_asset/ unaids-data-2018_en.pdf.

79. Church K, Kiweewa F, Dasgupta A, Mwangome M, Mpandaguta E, GómezOlivé FX, et al. A comparative analysis of national HIV policies in six African countries with generalized epidemics. Bull World Health Organ. 2015;93(7): 457-67.

80. Joint United Nations Programme on HIV/AIDS (UNAIDS). UNAIDS 2016-2021 Strategy: On the fast-track to end AIDS: UNAIDS Geneva; 2015 [Available from: https://www.unaids.org/sites/default/files/media_asset/20151027_ UNAIDS_PCB37_15_18_EN_rev1.pdf.

81. Mellins CA, Malee KM. Understanding the mental health of youth living with perinatal HIV infection: lessons learned and current challenges. J Int AIDS Soc. 2013;16:1-19.

82. Von Elm E, Altman DG, Egger M, Pocock SJ, Gøtzsche PC, Vandenbroucke $J P$, et al. The strengthening the reporting of observational studies in epidemiology (STROBE) statement: guidelines for reporting observational studies. Int J Surg. 2014;12(12):1495-9.

83. Tong A, Sainsbury P, Craig J. Consolidated criteria for reporting qualitative research (COREQ): a 32-item checklist for interviews and focus groups. Int J Qual Health Care. 2007;19(6):349-57.

84. Tracy SJ. Qualitative quality: eight "big-tent" criteria for excellent qualitative research. Qual Inq. 2010;16(10):837-51.

85. Mays N, Pope C. Qualitative research in health care: assessing quality in qualitative research. Br Med J. 2000;320:50-2.

86. Barnett-Page $\mathrm{E}$, Thomas J. Methods for the synthesis of qualitative research: a critical review. BMC Med Res Methodol. 2009;9:1-11.

87. Atkins S, Lewin S, Smith H, Engel M, Fretheim A, Volmink J. Conducting a meta-ethnography of qualitative literature: lessons learnt. BMC Med Res Methodol. 2008;8(1):1-10.

88. Lewin S, Bohren M, Rashidian A, Munthe-Kaas H, Glenton C, Colvin CJ, et al. Applying GRADE-CERQual to qualitative evidence synthesis findings-paper 2: how to make an overall CERQual assessment of confidence and create a summary of qualitative findings table. Implement Sci. 2018;13(1):11-23.

89. Diener E, Ryan K. Subjective well-being: a general overview. S Afr J Psychol. 2009;39(4):391-406.

90. Woollett N, Cluver L, Bandeira M, Brahmbhatt H. Identifying risks for mental health problems in HIV positive adolescents accessing HIV treatment in Johannesburg. J Child Adolesc Ment Health. 2017;29(1):11-26.

91. Earnshaw VA, Kidman RC, Violari A. Stigma, depression, and substance use problems among perinatally HIV-infected youth in South Africa. AIDS Behav. 2018;22(12):3892-6. 
92. Gentz SG, Calonge Romano I, Martinez-Arias R, Ruiz-Casares M. Predictors of mental health problems in adolescents living with HIV in Namibia. Child Adolesc Mental Health. 2017;22:179-85.

93. Kim MH, Mazenga AC, Yu X, Devandra A, Nguyen C, Ahmed S, et al. Factors associated with depression among adolescents living with HIV in Malawi. BMC Psychiatry. 2015;15:1-12.

94. Okawa S, Kabaghe SM, Mwiya M, Kikuchi K, Jimba M, Kankasa C, et al. Psychological well-being and adherence to antiretroviral therapy among adolescents living with HIV in Zambia. AIDS Care. 2018;30(5):634-42.

95. Mbalinda SN, Kiwanuka N, Kaye DK, Eriksson LE. Reproductive health and lifestyle factors associated with health-related quality of life among perinatally HIV-infected adolescents in Uganda. Health Qual Life Outcomes. 2015:13:1-11.

96. Mutumba M, Bauermeister JA, Harper GW, Musiime V, Lepkowski J, Resnicow K, et al. Psychological distress among Ugandan adolescents living with HIV: examining stressors and the buffering role of general and religious coping strategies. Global Public Health. 2017;12(12):1479-91.

97. Gaitho D, Kumar M, Wamalwa D, Wambua GN, Nduati R. Understanding mental health difficulties and associated psychosocial outcomes in adolescents in the HIV clinic at Kenyatta National Hospital, Kenya. Ann General Psychiatry. 2018;17(1):1-9.

98. Abebe H, Shumet S, Nassir Z, Agidew M, Abebaw D. Prevalence of depressive symptoms and associated factors among HIV-positive youth attending ART follow-up in Addis Ababa, Ethiopia. AIDS Res Treat. 2019; 2019:1-7.

99. Dow DE, Turner EL, Shayo AM, Mmbaga B, Cunningham CK, O'Donnell K. Evaluating mental health difficulties and associated outcomes among HIVpositive adolescents in Tanzania. AIDS Care. 2016;28(7):825-33.

100. Li RJ, Jaspan HB, O'Brien V, Rabie H, Cotton MF, Nattrass N. Positive futures: a qualitative study on the needs of adolescents on antiretroviral therapy in South Africa. AIDS Care. 2010;22(6):751-8.

101. Matovu SN. La cour K, Hemmingsson H. narratives of Ugandan women adhering to HIV/AIDS medication. Occup Ther Int. 2012;19(4):176-84.

102. Mutumba M, Bauermeister JA, Musiime V, Byaruhanga J, Francis K, Snow RC, et al. Psychosocial challenges and strategies for coping with HIV among adolescents in Uganda: a qualitative study. AIDS Patient Care STDs. 2015 29(2):86-94.

103. Mattes D. "Life is not a rehearsal, it's a performance": an ethnographic enquiry into the subjectivities of children and adolescents living with antiretroviral treatment in northeastern Tanzania. Child Youth Serv Rev. 2014;45:28-37.

104. Petersen I, Bhana A, Myeza N, Alicea S, John S, Holst H, et al. Psychosocial challenges and protective influences for socio-emotional coping of HIV plus adolescents in South Africa: a qualitative investigation. AIDS Care. 2010; 22(8):970-8.

105. Kyaddondo D, Wanyenze RK, Kinsman J, Hardon A. Disclosure of HIV status between parents and children in Uganda in the context of greater access to treatment. J Soc Aspects of HIV/AIDS Research Alliance. 2013;10(Suppl 1):37-45.

106. Siu GE, Bakeera-Kitaka S, Kennedy CE, Dhabangi A, Kambugu A. HIV serostatus disclosure and lived experiences of adolescents at the transition Clinic of the Infectious Diseases Clinic in Kampala, Uganda: a qualitative study. AIDS Care. 2012;24(5):606-11.

107. Jena PP. Exploring the lived experiences of adolescents living with vertically acquired HIV: University of South Africa; 2014.

108. Pienaar L, Visser MJ. An exploration of the experiences of adolescents living with HIV. Vulnerable Children Youth Studies. 2012;7(1):66-74.

109. Lypen KD, Lockwood NM, Shalabi F, Harper GW, Ngugi E. "when we are together I feel at home." types and sources of social support among youth newly diagnosed with HIV in Kenya: implications for intervention. Afr J AIDS Res. 2015;14(3):275-84

110. Abubakar A, Van de Vijver FJR, Fischer R, Hassan AS, Gona JK, Dzombo JT, et al. 'Everyone has a secret they keep close to their hearts': challenges faced by adolescents living with HIV infection at the Kenyan coast. BMC Public Health. 2016;16:197.

111. Rosenbaum L. Exploring the social ecological actors that contribute to the resilience of adolescents living with HIV in South Africa: a photovoice study. USA: The Chicago School of Professional Psychology, United States of America; 2017

112. Knizek BL, Mugisha J, Osafo J, Kinyanda E. Growing up HIV-positive in Uganda: "psychological immunodeficiency"? A qualitative study. BMC Psychology. 2017;5(1):1-10.
113. Vale B, Hodes R, Cluver L. Negotiations of blame and care among HIVpositive mothers and daughters in South Africa's eastern cape. Med Anthropol Q. 2017;31(4):519-36.

114. Shabalala F, De Lannoy A, Moyer E, Reis R. Rethinking the family in the context of care for adolescents living with HIV in Swaziland. AIDS Care. 2016;28:8-17.

115. Goudge J, Ngoma B, Manderson L, Schneider H. Stigma, identity and resistance among people living with HIV in South Africa. J Social Aspects of HIV/AIDS Research Alliance. 2009;6(3):94-104.

116. Plattner IE, Meiring N. Living with HIV: the psychological relevance of meaning making. AIDS Care. 2006;18(3):241-5.

117. Woollett N, Black V, Cluver L, Brahmbhatt H. Reticence in disclosure of HIV infection and reasons for bereavement: impact on perinatally infected adolescents' mental health and understanding of HIV treatment and prevention in Johannesburg, South Africa. Afr J AIDS Res. 2017:16(2):175-84.

118. Dusabe-Richards E, Rutakumwa R, Zalwango F, Asiimwe A, Kintu E, Ssembajja F, et al. Dealing with disclosure: perspectives from HIV-positive children and their older carers living in rural South-Western Uganda. Afr J AIDS Res. 2016:15(4):387-95.

119. Mackworth-Young CR, Bond V, Wringe A, Konayuma K, Clay S, Chiiya C, et al. "my mother told me that I should not": a qualitative study exploring the restrictions placed on adolescent girls living with HIV in Zambia. J Int AIDS Soc. 2017;20(4):1-7.

120. Kajubi P, Katahoire AR, Kyaddondo D, Whyte SR. Communication in the context of family caregiving: an exploratory study of Ugandan children on antiretroviral therapy. J Biosoc Sci. 2016;48(5):672-93.

121. Midtbo V, Shirima V, Skovdal M, Daniel M. How disclosure and antiretroviral therapy help HIV-infected adolescents in sub-Saharan Africa cope with stigma. Afr J AIDS Res. 2012;11(3):261-71.

122. Adegoke CO, Steyn MG. A photo voice perspective on factors contributing to the resilience of HIV positive Yoruba adolescent girls in Nigeria. $J$ Adolesc. 2017:56:1-10.

123. Mburu G, Hodgson I, Kalibala S, Haamujompa C, Cataldo F, Lowenthal ED, et al. Adolescent HIV disclosure in Zambia: barriers, facilitators and outcomes. J Int AIDS Soc. 2014;17:1-9.

124. Bernays S, Paparini S, Seeley J, Rhodes T. "not taking it will just be like a sin": Young people living with HIV and the stigmatization of less-than-perfect adherence to antiretroviral therapy. Med Anthropol. 2017:36(5):485-99.

125. Woollett N, Cluver L, Hatcher AM, Brahmbhatt H. "To be HIV positive is not the end of the world": resilience among perinatally infected HIV positive adolescents in Johannesburg. Child Youth Serv Rev. 2016;70:269-75.

126. Mathur S, Higgins JA, Thummalachetty N, Rasmussen M, Kelley L, Nakyanjo $\mathrm{N}$, et al. Fatherhood, marriage and HIV risk among young men in rural Uganda. Culture Health Sexuality. 2016;18(5):538-52.

127. Campbell C, Skovdal M, Mupambireyi Z, Madanhire C, Nyamukapa C, Gregson S. Building adherence-competent communities: factors promoting children's adherence to anti-retroviral HIV/AIDS treatment in rural Zimbabwe. Health Place. 2012;18(2):123-31.

128. Helliwell JF, Putnam R. The social context of well-being. Philos Trans R Soc Lond Ser B Biol Sci. 2004;359(1449):1435-46.

129. Huang X, Western M, Bian Y, Li Y, Côté R, Huang Y. Social networks and subjective wellbeing in Australia: new evidence from a national survey. Sociology. 2019:53(2):401-21.

130. Goswami H. Social relationships and children's subjective well-being. Soc Indic Res. 2012;107(3):575-88.

131. Greeff M, Uys LR, Wantland D, Makoae L, Chirwa M, Dlamini P, et al. Perceived HIV stigma and life satisfaction among persons living with HIV infection in five African countries: a longitudinal study. Int J Nurs Stud. 2010;47(4):475-86.

132. Hutton VE, Misajon R, Collins FE. Subjective wellbeing and 'felt' stigma when living with HIV. Qual Life Res. 2013;22(1):65-73.

133. Goffman E. Stigma: notes on the Management of Spoiled Identity. New York: Simon and Schuster; 1963.

134. Inzaule SC, Hamers RL, Kityo C, Rinke de Wit TF, Roura M. Long-Term Antiretroviral Treatment Adherence in HIV-Infected Adolescents and Adults in Uganda: A Qualitative Study. PLoS One. 2016;11(11):e0167492.

135. King V, Boyd LM, Pragg B. Parent-adolescent closeness, family belonging, and adolescent well-being across family structures. J Fam Issues. 2018;39(7): 2007-36.

136. Crespo C, Kielpikowski M, Pryor J, Jose PE. Family rituals in New Zealand families: links to family cohesion and adolescents' well-being. J Fam Psychol. 2011;25(2):184-93. 
137. Goodman ML, Gibson DC, Keiser PH, Gitari S, Raimer-Goodman L. Family, belonging and meaning in life among semi-rural Kenyans. J Happiness Stud. 2018;20:1627-45.

138. Leme VBR, Del Prette ZAP, Coimbra S. Social skills, social support and wellbeing in adolescents of different family configurations. Paidéia (Ribeirão Preto). 2015;25(60):9-17.

139. Sanjuán P, Molero F, Fuster MJ, Nouvilas E. Coping with HIV related stigma and well-being. J Happiness Stud. 2013;14(2):709-22.

140. Damon W, Menon J, Cotton BK. The development of purpose during adolescence. Appl Dev Sci. 2003;7(3):119-28.

141. Patel CJ, Ramgoon S, Paruk Z. Exploring religion, race and gender as factors in the life satisfaction and religiosity of Young south African adults. S Afr J Psychol. 2009;39(3):266-74.

142. Aghababaei N, Sohrabi F, Eskandari H, Borjali A, Farrokhi N, Chen ZJ. Predicting subjective well-being by religious and scientific attitudes with hope, purpose in life, and death anxiety as mediators. Pers Individ Dif. 2016; 90:93-8.

143. Roberts B, Struwig J, Gordon S, Ngungu M, Jordaan A. Quality of Life in South Africa and Algeria: SASAS 2012 tabulation report 2013 [Available from: http://www.hsrc.ac.za/en/research-outputs/view/6244.

144. Casas F, Sarriera JC, Alfaro J, González M, Malo S, Bertran I, et al. Testing the personal wellbeing index on 12-16 year-old adolescents in 3 different countries with 2 new items. Soc Indic Res. 2012;105(3):461-82.

145. Savahl S, Adams S, Isaacs S, September R, Hendricks G, Noordien Z. Subjective well-being amongst a sample of south African children: a descriptive study. Child Indic Res. 2015;8(1):211-26.

146. Rose T, Joe S, Williams A, Harris R, Betz G, Stewart-Brown S. Measuring mental wellbeing among adolescents: a systematic review of instruments. J Child Fam Stud. 2017;26:2349-62

147. Oishi S. Culture and well-being: Conceptual and methodological issues. In: Diener E, Kahneman D, Helliwell J, editors. International Differences in WellBeing 34. New York: Oxford University Press; 2010. p. 69.

148. Møller V, Roberts B, Zani D. The personal wellbeing index in the south African isiXhosa translation: a qualitative focus group study. Soc Indic Res. 2015;124(3):835-62.

149. Lall P, Lim SH, Khairuddin N, Kamarulzaman A. An urgent need for research on factors impacting adherence to and retention in care among HIVpositive youth and adolescents from key populations. J Int AIDS Soc. 2015; 18:41-53.

150. Krug A, Hildebrand M, Sun N. "We don't need services. We have no problems": exploring the experiences of young people who inject drugs in accessing harm reduction services. J Int AIDS Soc. 2015;18:71-7.

151. Napierala S, Chabata ST, Fearon E, Davey C, Hargreaves J, Busza J, et al. Engagement in HIV care among young female sex workers in Zimbabwe. J Acquir Immune Defic Syndr. 2018;79(3):358-66.

152. Vreeman RC, McCoy BM, Lee S. Mental health challenges among adolescents living with HIV. J Int AIDS Soc. 2017;20(S3):100-9.

153. Kim S-H, Gerver SM, Fidler S, Ward H. Adherence to antiretroviral therapy in adolescents living with HIV: systematic review and meta-analysis. AIDS 2014;28(13):1945-56.

154. Hudelson C, Cluver L. Factors associated with adherence to antiretrovira therapy among adolescents living with HIV/AIDS in low- and middleincome countries: a systematic review. AIDS Care. 2015;27(7):805-16.

\section{Publisher's Note}

Springer Nature remains neutral with regard to jurisdictional claims in published maps and institutional affiliations.

Ready to submit your research? Choose BMC and benefit from:

- fast, convenient online submission

- thorough peer review by experienced researchers in your field

- rapid publication on acceptance

- support for research data, including large and complex data types

- gold Open Access which fosters wider collaboration and increased citations

- maximum visibility for your research: over $100 \mathrm{M}$ website views per year

At $\mathrm{BMC}$, research is always in progress.

Learn more biomedcentral.com/submissions 